\title{
SUCCINYLATED STARCHES FOR DYE REMOVAL
}

\author{
Diana Soto ${ }^{1}$, Orietta León* ${ }^{* 1}$, Alexandra Muñoz-Bonilla ${ }^{2,3}$, Marta Fernandez-García ${ }^{2,3}$ \\ ${ }^{1}$ Laboratorio de Polímeros y Reacciones, Escuela de Ingeniería Química, Facultad de Ingeniería, \\ Universidad del Zulia, Sector Grano de Oro, Avenida 16 (Guajira), Ciudad Universitaria Dr. Antonio \\ Borjas Romero, Edificio Petróleo y Química, 4011 Maracaibo, Venezuela \\ 2 Departamento de Química y Propiedades de Materiales Poliméricos, Instituto de Ciencia y \\ Tecnología de Polímeros (CSIC), C/ Juan de la Cierva 3, 28006 Madrid, Spain \\ ${ }^{3}$ Interdisciplinary Platform for Sustainable Plastics towards a Circular Economy-Spanish National \\ Council (SusPlast-CSIC), Madrid, Spain \\ *E-mail: orleon@fing.luz.edu.ve (O. L.), martafg@ictp.csic.es (M. F-G) \\ Telephone numbers: +58 4246735743 (O. León), +34-912587530 (M. F-G)
}

Keywords: starch; oxidation; succinylated starch, dyes; removal 


\section{Abstract}

Succinylated bitter cassava starches were evaluated for the removal of cationic, methylene blue (MB) and anionic, methyl orange (MO) dyes present in water. The native starch (NS) extracted from bitter cassava by the dry method, was modified using succinic anhydride (SA) as esterifying agent and sodium hydroxide $(\mathrm{NaOH})$, sodium carbonate $\left(\mathrm{Na}_{2} \mathrm{CO}_{3}\right)$, sodium sulfate $\left(\mathrm{Na}_{2} \mathrm{SO}_{4}\right)$ and sodium chloride $(\mathrm{NaCl})$ as non-toxic and environmentally friendly catalysts. The effect of the type and concentration of catalyst on the modification was evaluated. Starch replacement with SA was confirmed by Fourier transform infrared spectroscopy (FTIR), wide-angle X-ray diffraction (WAXS), thermogravimetric analysis (TGA), and scanning electron microscopy (SEM). The degree of substitution in the resulting succinylated starches (GS) was determined by volumetric analysis, presenting high values (0.5-0.9). These materials arisen superabsorbent gels, sensitive to changes in $\mathrm{pH}$ and ionic strength, and mostly with anti-polyelectrolytic behavior. MB dye had a higher affinity for succinylated starches than the MO dye. The removal capacity of MB was also influenced by the $\mathrm{pH}$ and the ionic strength of the solution. The kinetics and adsorption isotherms were satisfactorily adjusted to the pseudo-second order and Freundlich models, respectively. The esters functionalities of the starch proved to be reusable adsorbents, completing successfully five cycles of adsorption-desorption.

\section{Introduction}

The contamination of water in rivers, streams and lakes caused by the direct discharge into the environment of wastewater with high content of dyes used in various industrial processes, such as textiles, tanning, paper, food, pharmaceuticals and cosmetics, causes serious problems in aquatic life, provoking even the suppression of the photosynthetic process of some species. Drastic changes can also occur in the flora and fauna, when these dyes are discharged into the phreatic level, since the chemicals that contain the dyes have the disadvantages of being composed of complex, carcinogenic, mutagenic, toxic structures, with chromophores groups of high molar mass, high water solubility and difficult biodegradability. Not only do they affect the environment, but they can be also biomagnified through the food chain, causing damage to human life (some dyes cause allergies, dermatitis, skin irritation, cancer and reproductive system dysfunction, central nervous system, among others). It is estimated that between $10-15 \%$ of the dyes used in the aforementioned industries are thrown into wastewater ${ }^{[1-5]}$. 
Dyes present in the wastewater are difficult to remove due to their low concentration; in some cases the water coloration can be observed in dye concentrations lower than $1 \mathrm{mg} / \mathrm{L}$ $[1,2]$. The high cost to remove traces of impurities makes conventional methods of dye removal not feasible for large-scale use, including physical-chemical and biological treatment technologies, such as coagulation-flocculation, biological processes, reverse osmosis, membrane filtration, oxidation, electrolysis, ion exchange and adsorption ${ }^{[6-8]}$. Adsorption has been considered one of the best techniques due to its ease of operation, simplicity of design, high efficiency, profitability and reuse capacity. The adsorbents most used among other types are activated carbon, clays, biomass, and zeolites, both synthetic and natural polymeric materials ${ }^{[3,5]}$.

An interesting alternative to remove dyes present in water is through the use of unconventional starch-based adsorbents ${ }^{[1,9]}$. It is known that cassava (Manihot esculenta Crantz) is a botanical source rich in starch, which comprises essentially of a mixture of polysaccharides consisting of amylose and amylopectin as well as a minor fraction (1 to $2 \%$ ) of non-glucosidic conformation. In most starches, the glycosidic fraction consists of $20-30 \%$ amylose and 70-80\% amylopectin ${ }^{[10-12]}$. Bitter cassava varieties are intended for industrial use (due to their high cyanide content), while sweet cassava varieties are reserved for human consumption ${ }^{[13]}$. Starch has several advantages that position it as an excellent raw material at industrial level such as abundance, low cost and high availability in many countries. Regarding its physical, chemical and biological properties, it is worth highlighting its hydrophilicity, biodegradability, functionality, high chemical reactivity and adsorption capacity. Depending on the application, however, its hydrophilic nature is one of its main drawbacks, which limits its development. Chemical modification of starch is a success approach habitually used to solve this problem and produce water resistant materials ${ }^{[1,9,11,12,14]}$. Among the chemical modification methods succinylation to produce succinylated starch could offer some advantages. This method consists on an esterification reaction by adding succinic anhydride in aqueous medium using a base. During succinylation, the material can intersect in the form of a three-dimensional network, forming gels ${ }^{[15]}$.

Polymeric gels with different compositions have been used for the adsorption of cationic and anionic dyes. Gels with negative charges in their structures are effective in the removal of cationic dyes, while positively charged ones are suitable for the removal of anionic dyes, hybrid ion gels can be used for both cationic and anionic dyes ${ }^{[16-18]}$. However, the weak mechanical resistance of the gels is one of its drawbacks that limit its application especially for repeated adsorption cycles. 
In this work, bitter cassava starch was chemically modified by succinylation. Novel, nontoxic and environmentally friendly catalysts were implemented, such as $\mathrm{NaOH}, \mathrm{NaCl}$, $\mathrm{Na}_{2} \mathrm{CO}_{3}$ and $\mathrm{Na}_{2} \mathrm{SO}_{4}$ to promote starch esterification. These materials were extensively analyzed for dye removal applications.

\section{Experimental part}

\subsection{Materials}

Bitter cassava was obtained from Anzoátegui State and cultivated in Zulia State, Venezuela. The reagents used are the following: amylose (Sigma-Aldrich, 99\%), calcium chloride, $\mathrm{CaCl}_{2}$ (Sigma-Aldrich, $\geq 93.0 \%$ ), disodium hydrogen phosphate, $\mathrm{Na}_{2} \mathrm{HPO}_{4}$ (Scharlau, 98\%), ethanol, EtOH (Merck, 95\%), hydrochloric acid, $\mathrm{HCl}$ (Merck, 37\%), iodine, I (J.T. Baker, USA, 99.9\%), methyl orange, MO (Fisher Scientific), methylene blue, MB (Fisher Scientific), monosodium phosphate, $\mathrm{NaH}_{2} \mathrm{PO}_{4}$ (Sigma-Aldrich, $\geq 98 \%$ ), nitric acid, $\mathrm{HNO}_{3}$ (Fisher Scientific, 65\%), phenolphthalein (Aldrich, 98-102\%), potassium bromide, $\mathrm{KBr}$ (Riedel-de-Haen, Germany, 99.5\%), potassium iodide, KI (J.T. Baker, USA, $100 \%$ ), potassium permanganate, $\mathrm{KMnO}_{4}$ (Fisher Scientific, 99\%), sodium carbonate, $\mathrm{Na}_{2} \mathrm{CO}_{3}$ (Panrearc, 99.5\%,), sodium hydroxide, $\mathrm{NaCl}$ (Merck, 99\%), sodium hydroxide, $\mathrm{NaOH}$ (Merck, 99\%), sodium sulfite, $\mathrm{Na}_{2} \mathrm{SO}_{3}$ (Merck, 98\%), succinic anhydride, SA (Merck, $99 \%$ ), trisodium phosphate, $\mathrm{Na}_{3} \mathrm{PO}_{4} \cdot 12 \mathrm{H}_{2} \mathrm{O}$ (Sigma-Aldrich, $\geq 98 \%$ ). All the products were used as received.

\subsection{Extraction and characterization of starch from bitter cassava}

\section{Extraction}

The dry method established by the Food and Agriculture Organization of the United Nations (FAO) ${ }^{[19]}$ was used to extract bitter cassava starch. Cassava was washed with plenty of water, chipped until the purple coloration, typical of the bitter variety, was scratched and placed on a Tergal mesh on polypropylene containers. Then, distilled water was added to leach all the starch contained in the cassava, until the filtrate was translucent. Subsequently, the leachate was allowed to settle for $24 \mathrm{~h}$ until all the starch was collected at the bottom of the container. Finally, the suspended water was decanted and the starch in the polypropylene container was sun dried, crushed, sieved and stored until characterization. The extraction yield for el starch isolated from bitter cassava sample was determined to be $8.19 \%$.

Proximate analysis 
The analyses were carried out using standard methods ${ }^{[20]}$, including moisture content (method 925.09), crude protein (method 954.01), crude fat (method 920.39), crude fiber (method 962.09), ash content (method 923.03) and total content of carbohydrates estimated as nitrogen-free extracts (NFE). Native starch showed a humidity content percentage $=7.3 \pm 0.1 \%$, ash content $=0.50 \pm 0.01 \%$, fat $=0.043 \pm 0.01 \%$, raw proteins $=$ $0.53 \pm 0.03 \%$, null fiber and carbohydrate $=90.9 \pm 0.1 \%$.

\section{Amylose content}

The amylose content was determined by UV-vis spectroscopy using a Perkin Elmer spectrometer, Lambda 2, following a standard procedure (ISO 6647-1: 2015). For this, 100 $\mathrm{mg}$ of starch was weighed in an Erlenmeyer by adding $9 \mathrm{~mL}$ of $1 \mathrm{M} \mathrm{NaOH}$ solution, the mixture was heated in a water bath at $95^{\circ} \mathrm{C}$ for $15 \mathrm{~min}$. After this time, it was cooled down to room temperature with constant stirring, transferring the mixture to a $100 \mathrm{~mL}$ round-flask that was subsequently flushed with distilled water and stirred vigorously. This solution was called Dispersion A and subsequently, $2 \mathrm{~mL}$ of this dispersion was measured by adding it to $100 \mathrm{~mL}$ balls. This procedure was repeated by triplicate. Then, $3 \mathrm{~mL}$ of $0.09 \mathrm{M} \mathrm{NaOH}$ solution was added to the round-flask, along with $6 \mathrm{~mL}$ of the Lugol solution, flush with 100 $\mathrm{mL}$ distilled water, mixed vigorously and allowed to stand for $10 \mathrm{~min}$; this solution was called Dispersion B. Then, $5 \mathrm{~mL}$ of Dispersion B was taken and its absorbance was measured at $\lambda_{\max }=590 \mathrm{~nm}$. Finally, the amylose concentration in the calibration curve was determined, amylose in solution (\%) ${ }^{[11]}$. The amylose content in starch was calculated by the equation 1 :

Amylose content $(\%)=[$ amylose in solution $(\%) / m S] \times F_{d}$

where amylose in solution $(\%)=f($ absorbance $), m S$ is the mass of the starch sample in $g$ and $F_{d}$ is the dilution factor. The amylose content was found to be $29 \pm 1 \%$.

\section{Differential scanning calorimetry, DSC}

The thermal behavior was analyzed using a Pyris 6 DSC calorimeter. Indium $\left(\Delta \mathrm{H}_{\mathrm{m}}=28.55\right.$ $\mathrm{J} / \mathrm{g}$ and $\mathrm{T}_{\mathrm{m}}=429.8 \mathrm{~K}$ ) was used as a calibration standard. For this, $10 \mathrm{mg}$ of the sample was placed in high pressure pans. $7.5 \mu \mathrm{L}$ of water (humidity $=75 \%$ ) was added and sealed with the aid of the die. The sealed pan was then weighed to quantify the added water, gently shaken for $5 \mathrm{~min}$ and allowed to reach the equilibrium for approximately $24 \mathrm{~h}$. At the same time a reference pan was sealed without sample and without water. Once equilibrated, the pans were placed with the sample and the reference in the equipment 
and heated from $25^{\circ} \mathrm{C}$ to $100^{\circ} \mathrm{C}$, with a heating rate of $5^{\circ} \mathrm{C} / \mathrm{min}$ in inert atmosphere. After the calorimetric scanning, the initial temperature of gelatinization was obtained, $T_{0}=66^{\circ} \mathrm{C}$, the peak temperature, $\mathrm{T}_{\mathrm{p}}=73^{\circ} \mathrm{C}$ and the final temperature, $\mathrm{T}_{\mathrm{c}}=79{ }^{\circ} \mathrm{C}$ as well as the enthalpy of gelatinization, $\Delta \mathrm{H}_{\mathrm{gel}}=2.36 \mathrm{~J} / \mathrm{g}$.

\subsection{Succinylation of bitter cassava starch}

To modify the extracted cassava starch, seven esterification reactions in aqueous medium were carried out with $\mathrm{SA}$, in which the substrate pretreatment, the catalyst $(\mathrm{NaOH}$, $\mathrm{Na}_{2} \mathrm{SO}_{4}, \mathrm{NaOH} / \mathrm{NaCl}$ and $\mathrm{Na}_{2} \mathrm{CO}_{3}$ ) and the concentration were varied. Scheme 1 represents the chemical reaction of starch by SA.<smiles></smiles>

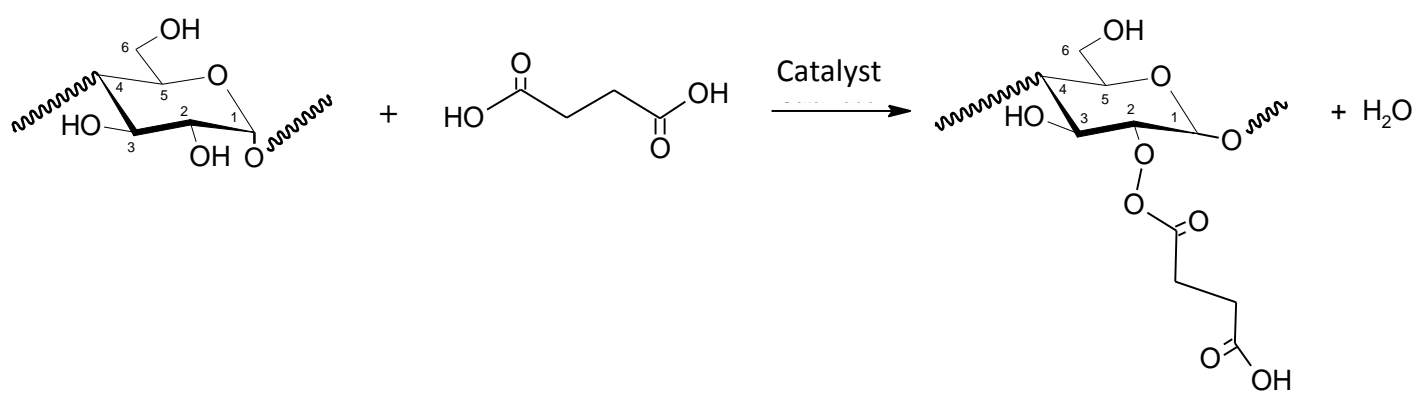

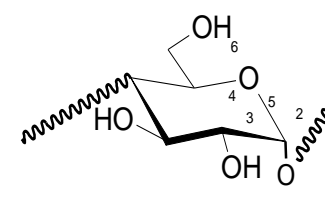<smiles>O=C(O)CCC(=O)O</smiles>

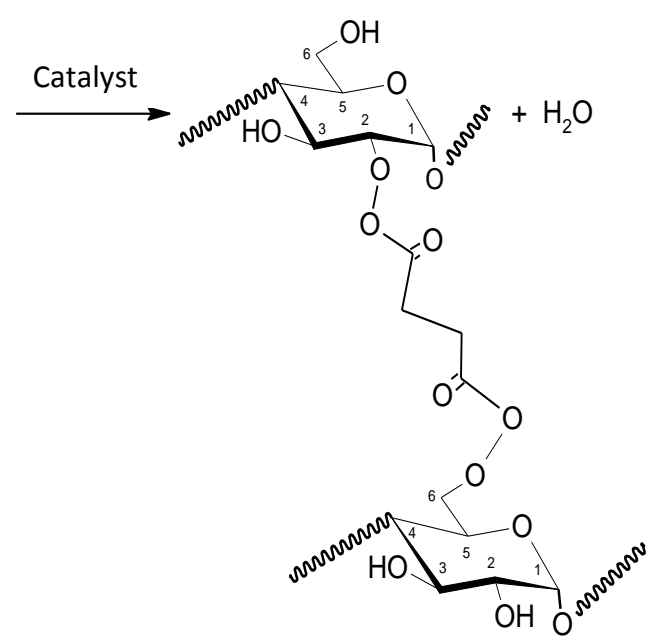

(c)

Scheme 1. (a) Ring opening of succinic anhydride, (b) Mono-substitution of succinic anhydride on starch and (c) Di-substitution of succinic anhydride on starch. 
The procedure used by Kweon et al. ${ }^{[21]}$ was followed with some modifications. For reaction $E 1,10 \mathrm{~g}$ of starch ( $0.62 \mathrm{M}$ of anhydroglucose units, AGU) were weighed into a beaker, and then, $5 \mathrm{~g}$ of SA (5 M) were weighed and added to the beaker containing the starch. Subsequently, $100 \mathrm{~mL}$ of distilled water was added and stirred. Then, $1 \mathrm{M} \mathrm{NaOH}$ was added until $\mathrm{pH}=9$ at $30^{\circ} \mathrm{C}$. The reaction was allowed for $3 \mathrm{~h}$ and with constant stirring. After the reaction time, it was brought to $\mathrm{pH}=6$ with $\mathrm{HCl}$. Finally, it was slowly precipitated with $200 \mathrm{~mL}$ of ethanol.

The same procedure described for $\mathrm{E} 1$ was carried out for the rest of the reactions but varying the catalyst system. Instead of $1 \mathrm{M} \mathrm{NaOH}, 0.01 \mathrm{mM} \mathrm{Na}_{2} \mathrm{CO}_{3}$ was used for $\mathrm{E} 2,0.02$ $\mathrm{mM} \mathrm{Na}_{2} \mathrm{CO}_{3}$ for E3, $0.02 \mathrm{mM} \mathrm{Na}_{2} \mathrm{SO}_{4}$ for E4, $0.02 \mathrm{mM} \mathrm{NaOH} / \mathrm{NaCl}$ for E5 and $0.03 \mathrm{mM}$ $\mathrm{Na}_{2} \mathrm{CO}_{3}$ for $\mathrm{E} 7$. The final $\mathrm{pH}$ of these reactions was that provided by the hydrolysis of the salt used as a catalyst and by the unreacted SA. In the case of $\mathrm{E} 5(\mathrm{NaOH} / \mathrm{NaCl}=0.02$ $\mathrm{mM}), 1 \mathrm{M} \mathrm{NaOH}$ solution was later added to reach $\mathrm{pH}=9$ necessary to the reaction. Finally, the mixture was brought to $\mathrm{pH}=6$ with $\mathrm{HCl}$.

For $\mathrm{E} 6\left(\mathrm{NaOH}, \mathrm{pH}=9,1 \times 10^{-5} \mathrm{M}\right)$ the starch was pre-gelatinized at a temperature of $75^{\circ} \mathrm{C}$ for $15 \mathrm{~min}$ with $80 \mathrm{~mL}$ of distilled water and constant stirring.

To purify the products obtained, successive washes were performed with water/ethanol $(50 / 50)$ solution. The initial $\mathrm{pH}$ of the washed solution was measured and the filtered products were washed until the $\mathrm{pH}$ of the washed mixture was equal to or very close to that of the initial solution and the Lugol test was negative. After this, the products were dried at $40{ }^{\circ} \mathrm{C}$ until constant weight, pulverized, sieved and stored on $\mathrm{CaCl}_{2}$ until characterization and application.

\subsection{Degree of substitution of succinylated starches}

To quantify the degree of substitution, $0.25 \mathrm{~g}$ of the succinylated starch was weighed in a $25 \mathrm{~mL}$ Erlenmeyer. Then, $6.25 \mathrm{~mL}$ of a $2.5 \mathrm{M} \mathrm{HCl} /$ isopropyl alcohol solution in the Erlenmeyer containing the sample was added and stirred for $30 \mathrm{~min}$. After stirring time the solutions were filtered and washed with $25 \mathrm{~mL}$ of isopropyl alcohol and later with $75 \mathrm{~mL}$ of water.

These solutions were heated at $90^{\circ} \mathrm{C}$ for $10 \mathrm{~min}$ with constant stirring. After the heating time, they were allowed to stand at room temperature with continuous stirring, then four drops of phenolphthalein were added and titrated with $1 \mathrm{M} \mathrm{NaOH}$ to $\mathrm{pH} 8.4{ }^{[21]}$. All the titrations were made in triplicate. With the volume of titrant consumed, the degree of substitution was calculated using Equation 2. 


$$
\mathrm{DS}=\frac{0.162 \times(\mathrm{A} \times \mathrm{N}) / \mathrm{W}}{1-[0.101 \times(\mathrm{A} \times \mathrm{N}) / \mathrm{W}]}
$$

Where $\mathrm{A}$ is the used volume of $\mathrm{NaOH}$ in $\mathrm{mL}, \mathrm{N}$ is the normal $\mathrm{NaOH}$ in the solution and $\mathrm{W}$ is the mass of succinylated starch in $\mathrm{g}$.

\subsection{Determination of apparent viscosity}

The apparent viscosity of the starch samples was made over a shear rate from 50 to 1300 $\mathrm{s}^{-1}$ at $80^{\circ} \mathrm{C}$ using a Haake rotovisco RV 20.

\subsection{Zeta Potential}

The zeta potential values were measured at $25^{\circ} \mathrm{C}$ in a Zetasizer Nano ZS, from Malvern Instruments (UK), which is equipped with a He-Ne laser beam at $633 \mathrm{~nm}$. The zeta potential values were averaged over at least 10 runs.

\subsection{Fourier transform infrared spectroscopy (FTIR)}

The infrared spectra of starches were recorded using a Fourier transform infrared spectrometer Shimadzu IR Prestige-21, in the region of $4000-400 \mathrm{~cm}^{-1}$. The spectra resolution was $4 \mathrm{~cm}^{-1}$ and 100 scans were averaged for each spectrum. Pellets were obtained by mixing the sample previously dried, with $\mathrm{KBr}$ at a ratio of $1: 100$ (sample: $\mathrm{KBr}$ ). FTIR spectrum of succinylated starch, $\left(\mathrm{KBr}, \mathrm{cm}^{-1}\right): 3550-3200(\mathrm{vO}-\mathrm{H}$ of starch and $\mathrm{vOH}$, $\mathrm{COOH}$ of AS), 2926 ( $v_{\mathrm{as}} \mathrm{C}-\mathrm{H}, \mathrm{CH}_{2}$ of starch), $2990\left(v_{\mathrm{s}} \mathrm{C}-\mathrm{H}, \mathrm{CH}_{2}\right.$ of SA), $2853\left(v_{\mathrm{s}} \mathrm{C}-\mathrm{H}, \mathrm{CH}_{2}\right.$ of starch), 1775-1650 ( $v \mathrm{C}=\mathrm{O}, \mathrm{C}-\mathrm{C}(\mathrm{O})-\mathrm{C}$ of SA), 1760 ( $v \mathrm{C}=\mathrm{O}, \mathrm{COOH}$ of $\mathrm{AS}), 1643\left(\delta_{\mathrm{s}} \mathrm{H}-\mathrm{O}-\mathrm{H}\right.$, $\mathrm{H}_{2} \mathrm{O}$ ), 1610-1550 ( $v_{\mathrm{as}} \mathrm{COO}^{-}$of $\left.\mathrm{SA}\right), 1465\left(\delta_{\mathrm{s}} \mathrm{C}-\mathrm{H}, \mathrm{CH}_{2}\right.$ of starch and SA), 1450-1400 $\left(v_{\mathrm{s}} \mathrm{COO}^{-}\right.$of SA), 1440-1395 ( $\mathrm{OO}-\mathrm{H}, \mathrm{COOH}$ of SA), $1423(\mathrm{vC}-\mathrm{H}, \mathrm{AGU}), 1420-1330\left(\delta_{\mathrm{ip}} \mathrm{O}-\mathrm{H}\right.$ of starch), 1420, 1330 coupling $\left(\delta_{i p} \mathrm{O}-\mathrm{H}, \omega \mathrm{C}-\mathrm{H}\right.$ of starch), 1385-1380, 1760-1366 $(\delta \mathrm{C}-\mathrm{H}, \mathrm{C}-$ $\mathrm{H}$ of starch), $1350-1150\left(\omega, \gamma \mathrm{C}-\mathrm{H}\right.$ of $\mathrm{CH}_{2}$ of starch and SA), 1320-1210 ( $\mathrm{CC}-\mathrm{O}, \mathrm{COOH}$ of AS), 1200-1000 ( $v \mathrm{C}-\mathrm{O}$, of secondary $\mathrm{OH}$ of starch), 1160-1085 ( $\mathrm{vas}_{\mathrm{as}} \mathrm{C}-\mathrm{O}-\mathrm{C}, \mathrm{AGU}$ of starch), 1085-1050 (vC-O, C-C-O of starch), 926 ( $v A G U), 920\left(\delta_{o o p} \mathrm{OH}, \mathrm{COOH}\right.$ of SA), $720(\rho \mathrm{C}-\mathrm{H}$, $\mathrm{CH}_{2}$ of starch).

\subsection{Wide angle X-ray diffraction (WAXS)}

X-ray diffraction patterns of succinylated and native starches were obtained in a Bruker D8 Advance diffractometer equipped with a Goebel mirror and a position sensitive detector (PSD, Vantec) detector using $\mathrm{Cu}-\mathrm{K}_{\alpha}$ radiation and calibrated with various standards. The diffractograms were recorded between $5^{\circ}$ and $35^{\circ} 2 \theta$, with a $2 \theta$ step of $0.02^{\circ}$ and $0.2 \mathrm{~s}$ per 
step. The WAXS degree of crystallinity, Fc, was determined from deconvolution of X-ray profiles into crystalline diffractions and the amorphous halo ${ }^{[22]}$.

\subsection{Thermogravimetric analysis (TGA)}

The thermogravimetric analysis was performed on a TGA Q500 (TA Instruments). The instrument was calibrated in temperature and mass by standard methods. The dynamic experiments were performed in air at a heating rate of $10^{\circ} \mathrm{C} / \mathrm{min}$ in the temperature range between 40 and $800{ }^{\circ} \mathrm{C}$. The average sample size was approximately $5 \mathrm{mg}$ and the air flow rate was $20 \mathrm{~cm}^{3} / \mathrm{min}$. The activation energy $\left(E_{a}\right)$ of the decomposition of the samples was calculated by the Broido method ${ }^{[23]}$ as follows:

$$
\ln \left[\ln \left(\frac{1}{Y}\right)\right]=-\frac{E_{a}}{R} \times \frac{1}{T}+\text { constante }
$$

where $E_{a}$ is the activation energy, $R$ is the ideal gas constant, $T$ is the temperature in $K$ and $Y$ is the unconverted mass fraction, which is obtained from Equation 4:

$$
\mathrm{Y}=\frac{\mathrm{W}_{\mathrm{t}}-\mathrm{W}_{\infty}}{\mathrm{W}_{0}-\mathrm{W}_{\infty}}
$$

where $w_{t}$ is the mass of the sample at a temperature $T, w_{0}$ is the initial mass of the sample and $\mathbf{w}_{\infty}$ is the mass of ash recorded at the maximum temperature of the analysis.

\subsection{Scanning electron microscopy (SEM)}

The morphology of the bitter cassava starch and its esters was examined by scanning electron microscopy using a Philips XL30 microscope with an acceleration voltage of 25 $\mathrm{kV}$. The samples were coated with $5 \mathrm{~nm}$ of gold/palladium (80/20) prior visualization. SEM images were processed and quantified using the Fiji distribution of ImageJ software.

\subsection{Absorption capacity of succinylated starches}

The absorption capacity of succinylated starches was carried out by gravimetry in different media: water, saline solutions of $\mathrm{NaCl}, \mathrm{KCl}, \mathrm{MgCl}_{2}$ and $\mathrm{FeCl}_{3}$ at $0.9 \% \mathrm{~m} / \mathrm{v}$ and buffer solutions (between pH ranges between 4 and 10.11), using the tea-bag method.

$50 \mathrm{mg}$ of sample were weighed and placed in a previously weighed tea-bag and then, placed in a container with $400 \mathrm{~mL}$ of the corresponding medium at different times. After each time, the bag with the swollen sample was extracted, the excess water was allowed to drain and the bag was weighed with the previously drained sample. The absorption capacity of succinylated starches in the different media was calculated by Equation 5:

$$
H^{\infty}(\%)=\frac{W_{t^{\infty}}-W_{0}}{W_{0}} \times 100
$$


where $\mathrm{H}^{\infty}$ is the absorption capacity of the material in the equilibrium in percentage, $\mathrm{W}_{t}$ is the mass of the swollen material in $\mathrm{mg}$ and $\mathrm{W}_{0}$ is the initial mass of the material prior to immersion in $\mathrm{mg}$.

\subsection{Dye removal capacity}

In order to obtain the adsorption capacity of the succinylated starches loaded with the dye a certain amount of sample was weighed and placed in an Erlenmeyer, a known volume of the dye solution (MB or $\mathrm{MO}$ ) of a given concentration was added and heavily stirred in a shaker for a certain time at room temperature. After this time, the samples were centrifuged for $5 \mathrm{~min}$ at $85 \mathrm{rpm}$ and the transmittance was measured on UV-visible spectrophotometer model Genesys $10 \mathrm{~S}$ (Thermo Scientific brand) at $\lambda_{\max }=655 \mathrm{~nm}$ for MB and $\lambda_{\max }=463 \mathrm{~nm}$ for $\mathrm{MO}$. The residual concentration in the solution was determined in a calibration curve, constructed in advance from solutions of known dye concentrations. Adsorption capacity (q, mg dye/g starch) was calculated using Equation 6:

$$
\mathrm{q}=\frac{\mathrm{V} \times\left(\mathrm{C}_{\mathrm{i}}-\mathrm{C}_{\mathrm{E}}\right)}{\mathrm{m}}
$$

where $C_{i}$ and $C_{E}$ are the initial and residual concentrations of the dye in the solution in $\mathrm{mg} / \mathrm{L}$, respectively, $\mathrm{V}$ is the volume of dye solution in $\mathrm{L}$ and $\mathrm{m}$ is the starch mass in $\mathrm{g}$.

After each adsorption experiment, the remaining solution of the starches was removed, dried at $40{ }^{\circ} \mathrm{C}$ until constant weight and then, subjected to the desorption process. For this, a given amount of ethanol was added to the samples with the retained dye, applying the same procedure for the same period of time used in the adsorption. The conditions were maintained constant during all the experiments. The percentage of desorbed dye (PD) was determined from Equation $7^{\text {[24]: }}$

$$
\mathrm{PD}=\frac{\mathrm{C}_{\mathrm{des}}}{\mathrm{C}_{\mathrm{ad}}} \times 100
$$

where $\mathrm{C}_{\text {des }}$ is the amount of dye desorbed by the starches loaded in $\mathrm{mg} / \mathrm{L}$ and $\mathrm{C}_{\mathrm{ad}}$ is the amount of dye adsorbed by the starches in $\mathrm{mg} / \mathrm{L}$.

The modified starches were subjected to five cycles of adsorption-desorption under the conditions specified above. The removal efficiency $(\mathrm{RE})$ of the dyes on the adsorbents was estimated using Equation 8:

$$
R E=\left(\frac{C_{i}-C}{C_{i}}\right) \times 100
$$


where $\mathrm{C}$ is the concentration in the equilibrium of the dye in the solution in $\mathrm{mg} / \mathrm{L}$.

\section{RESULTS}

\subsection{Degree of substitution (DS) of succinylated starches}

Table 1 shows the DS of native starch (NS) and its derivatives, which were moderate for reactions carried out in aqueous medium, the DS values were confirmed by the zeta potential of the samples measured in water. The succinylation reaction occurs at C-2, C-3 and $\mathrm{C}-6$ sites of the native starch and is limited by the availability of $-\mathrm{OH}$ groups within the starch chain. The reaction will begin with the $-\mathrm{OH}$ that is less sterically hindered along the amylose, since is a linear chain, its $-\mathrm{OH}$ groups can be more easily substituted. Succinylation involves the substitution of the $-\mathrm{OH}$ in the native starch by $-\mathrm{COOH}$ groups provided by SA, which impart steric hindrance due to their large size, limiting the formation of inter- and intramolecular hydrogen bonds between the starch chains ${ }^{[11,25,26]}$. Shogren [27] indicates that the potential applications of succinylated starches are related to their DS, when they have medium to high grade DS (0.5-2.5), those present improved hydrophilic properties.

Table 1. DS, $F_{C}$ and Zeta potential values of starches.

\begin{tabular}{|c|c|c|c|c|c|}
\hline Sample & Catalyst & $\begin{array}{c}\text { Catalyst } \\
\text { concentration } \\
(\mathrm{mM})\end{array}$ & DS & $\begin{array}{c}F_{C} \\
(\%)\end{array}$ & $\begin{array}{c}\text { Zeta } \\
\text { potential } \\
(\mathrm{mV})\end{array}$ \\
\hline NS & NA & NA & NA & 38.4 & NA \\
\hline $\mathrm{E} 1$ & $\mathrm{NaOH}$ & 0.01 & 0.684 & 37.2 & $-32 \pm 2$ \\
\hline E2 & $\mathrm{Na}_{2} \mathrm{CO}_{3}$ & 0.01 & 0.535 & 37.1 & $-21 \pm 1$ \\
\hline E3 & $\mathrm{Na}_{2} \mathrm{CO}_{3}$ & 0.02 & 0.634 & 37.0 & $-30 \pm 2$ \\
\hline E4 & $\mathrm{Na}_{2} \mathrm{SO}_{4}$ & 0.02 & 0.549 & 37.6 & $-28 \pm 2$ \\
\hline E5 & $\mathrm{NaOH} / \mathrm{NaCl}$ & 0.02 & 0.691 & 37.7 & $-38 \pm 1$ \\
\hline$E 6^{a}$ & $\mathrm{NaOH}$ & 0.01 & 0.595 & NA & NA \\
\hline E7 & $\mathrm{Na}_{2} \mathrm{CO}_{3}$ & 0.03 & 0.859 & 36.9 & $-42 \pm 2$ \\
\hline
\end{tabular}

${ }^{a}$ Reaction with pre-gelatinized starch; NA: not applicable

When the succinylation was carried out with $\mathrm{NaOH}$ as a catalyst, a higher DS is found in the reaction with no gelatinized starch (E1) with respect to the pre-gelatinized starch (E6). Under the experimental conditions used for E6, the product obtained is a gel that could not be purified; therefore, E6 is discarded for next experiments. 
When using $\mathrm{Na}_{2} \mathrm{CO}_{3}$ as a catalyst for the succinylation reaction (E2, E3 and E7) at different concentrations, a significant effect was observed by increasing the salt concentration. An increase in catalyst concentration leads to an increase in DS. As the reaction was carried out in aqueous medium, the aggregate catalyst dissociates in the medium, generating charged ions that favor the breakdown of hydrogen bonds between the starch chains, thereby improving the access of the substituent to the $-\mathrm{OH}$ in the starch structure ${ }^{[28]}$. The nature of the ionic catalyst did not have an important effect on DS, as demonstrated in samples E3, E4 and E5.

The apparent viscosity of native bitter cassava starch and succinylated starches is shown in Figure 1. It is observed that the succinylation reaction undoubtedly changed the apparent viscosity of the modified starches, an increase in DS led to an increase in apparent viscosity. These results are in good agreement with what is described in the literature ${ }^{[29,30]}$.

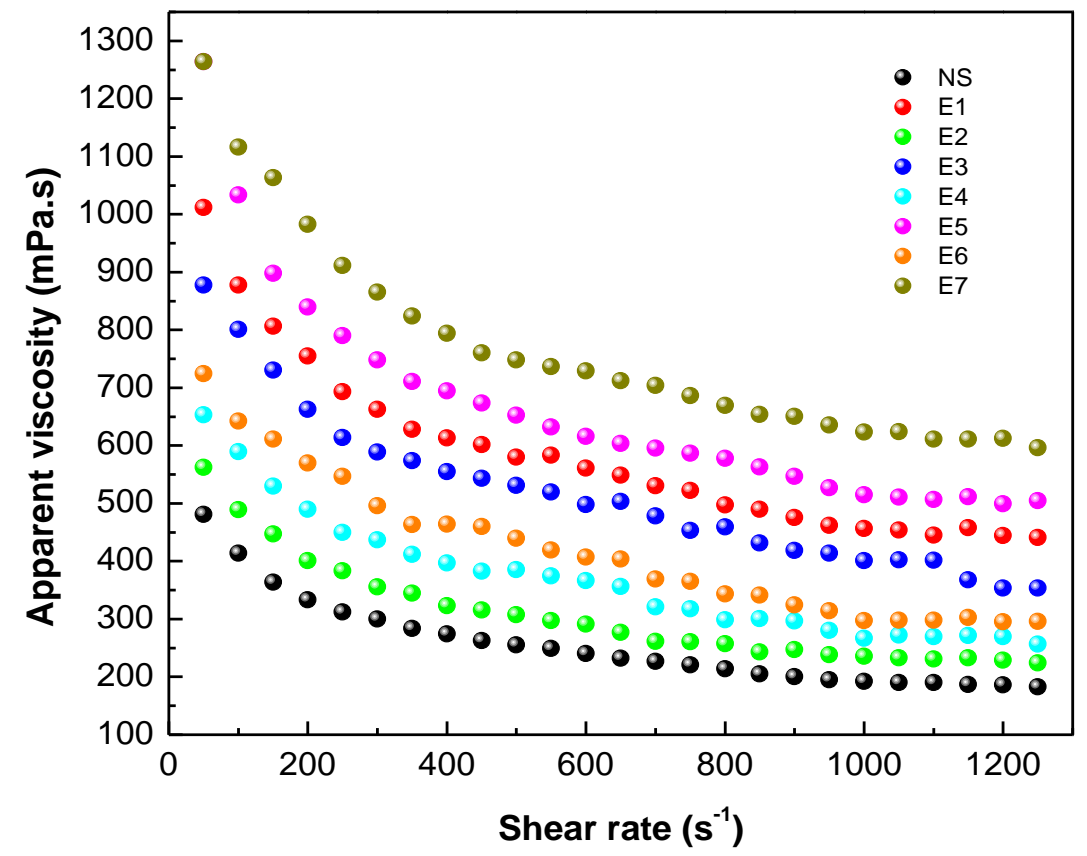

Figure 1. Apparent viscosity as a function of shear rate for the different samples

\subsection{Wide angle X-ray diffraction (WAXS)}

The diffractogram of the native starch is presented together with that of the succinylated starches in Figure 2. A diffraction pattern $A+B$ crystal type is observed in the diffractogram of the native starch. The strong intensity diffraction peaks at $2 \theta=15.09^{\circ}, 17.16^{\circ}, 18.00^{\circ}$ 
and $23.01^{\circ}$ characteristic of the $A$ type pattern and the weak diffraction peak at $2 \theta=5.62^{\circ}$ characteristic of the $B$ type are clearly observed. Various researchers ${ }^{[11-34]}$ have reported this type of pattern in roots Tuberous as cassava.

The succinylated starches showed diffraction peaks similar to those of the native starch with strong diffractions doublet at $2 \theta=17.0-17.2^{\circ}$ and $17.8-18.0^{\circ}$, two medium intensity peaks at $2 \theta=15.0-15.4^{\circ}$ and $22.9-23.1^{\circ}$, and low intensity peaks at $2 \theta=10.0-10.2^{\circ}, 11.2-$ $11.4^{\circ}, 20.0-20.1^{\circ}, 26.1-26.6^{\circ}, 28.6-29.0^{\circ}$ and $30.0-30.6^{\circ}$, where the characteristic peak of type $B$ patterns is found at $2 \theta=5.4-5.6^{\circ}$. Thus, all succinylated starches have a diffraction pattern type $A+B$, with the exception of $E 3$, where the diffraction peak at $2 \theta=5.6^{\circ}$ is notoriously absent, indicating that it changed its diffraction pattern to A-type.

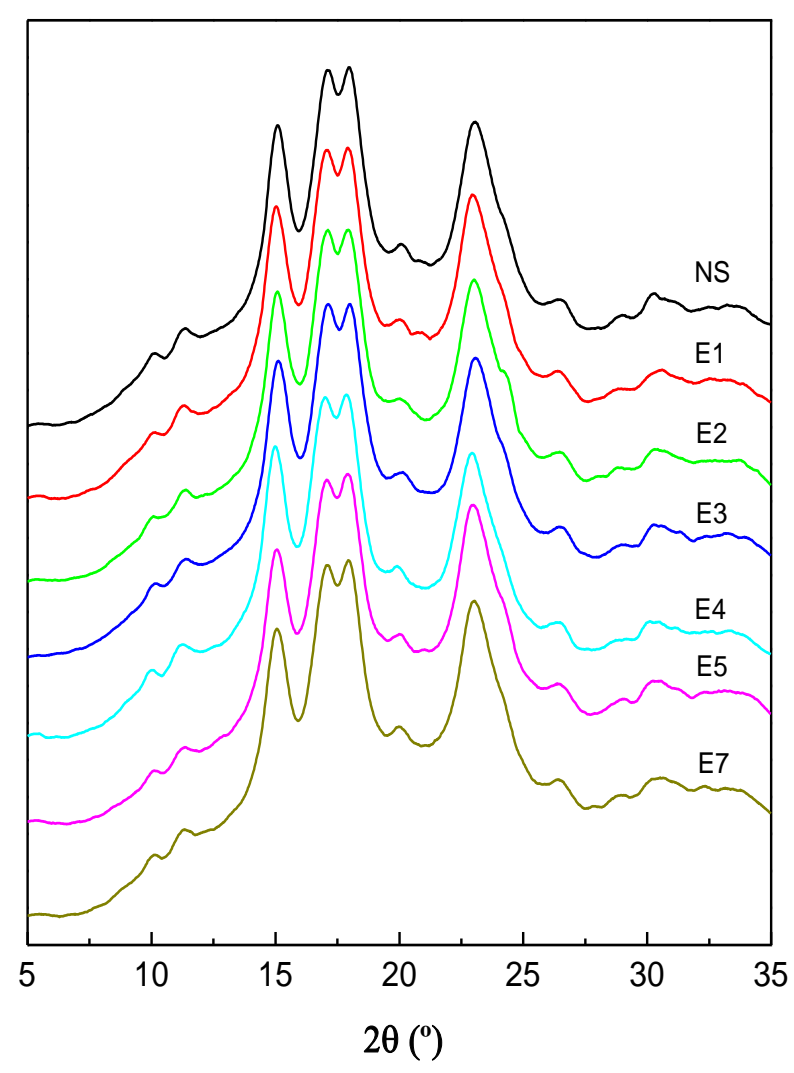

Figure 2. X-ray diffractograms of starch and its derivatives.

Table 1 also collects the crystalline fractions $\left(F_{C}\right)$ of the starch samples. All succinylated starches presented $F_{C}$ values slightly smaller with respect to the native starch. Several investigations ${ }^{[34,35]}$ have concluded that succinylation does not change the x-ray pattern of starches, that is, succinylation occurs mainly in amorphous regions of the starch granule. 


\subsection{Thermogravimetric analysis}

The thermal behavior of native starch and starch esters was studied by TGA. Figure 3 displays the thermograms of native and succinylated starches. The characteristics parameters of degradations are collected Table S1 in Supporting Information. As can be seen, starches have four stages of degradation. The first step corresponds to the evaporation of free and strongly linked water ${ }^{[14,36]}$. The second stage is attributed to the degradation of the carboxylic acid groups, present as a product of natural oxidation in the native starch and to the incorporation of the succinyl groups in the modified starches. Decarboxylation is primarily a chemical reaction in which a carboxyl groups are removed in form of $\mathrm{CO}_{2}$. The third step is assignable to the decomposition of the main polysaccharide chain, in which volatile compounds are formed, basically $\mathrm{H}_{2} \mathrm{O}, \mathrm{CO}, \mathrm{CO}_{2}, \mathrm{C}_{2} \mathrm{H}_{4}$, and $\mathrm{CH}_{2} \mathrm{O}$ ${ }^{[37-40]}$. The fourth stage with a loss of mass is attributable to the decomposition of pseudocrosslinks formed by the products generated in the main degradation. Finally, the residual mass at $800^{\circ} \mathrm{C}$ is revealed as a non-volatile product ${ }^{[39,40]}$.
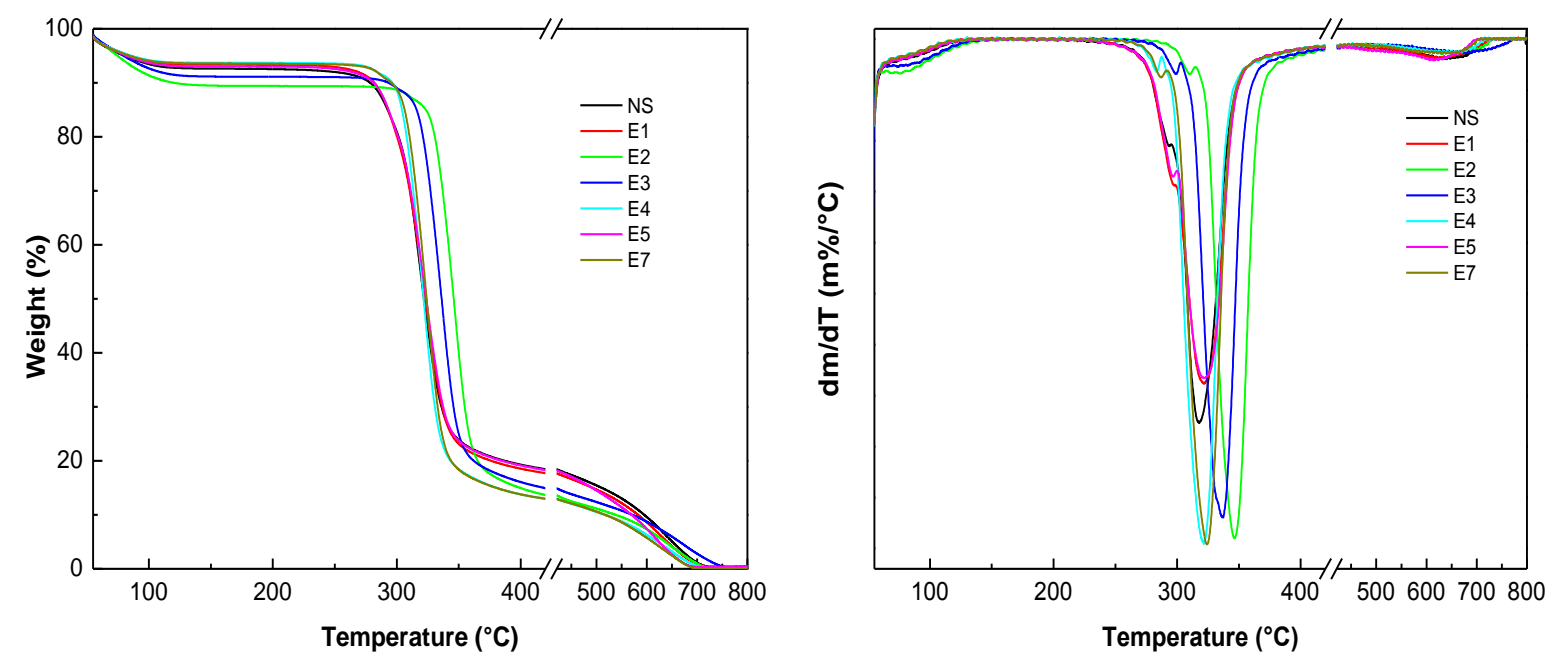

Figure 3. Thermograms (left) and derivative of thermograms curves (right) of native and succinylates starches.

The thermal stability of succinylated starches was compared with the stability of the native bitter cassava starch, taking as a criterion the starting temperature of decarboxylation stage, which evidences sharper and more defined peaks for esters E2, E3, E4 and E7, while a shoulder can be distinguished for NS, E1 and E5. This change on behavior is due to the increase in carboxyl groups derived from the substituted SA in the polysaccharide 
structure ${ }^{[40]}$. It should be noted that the decomposition starting temperature of succinylated starches increases in comparison with the native starch; what is attributed to the esterification reaction with the SA that leads to the reduction of the $-\mathrm{OH}$ groups in the starch chain. Notice that the main mechanism of starch decomposition is the result of interand intramolecular dehydration reactions ${ }^{[40,41]}$. It is important to remark that the increase in the catalyst concentration leads to higher substitution (E2, E3 and E7), which decreases the stability.

The apparent $E_{a}$ for the modified starches was calculated from the derivative of thermograms curves. $E_{a}$ values of the succinylated samples result higher than the corresponding to native starch, indicating that the degradation process is slower.

\subsection{Scanning electron microscopy (SEM)}

The morphology of all starches was analyzed by SEM. The granule size and the distribution of native and succinylated starches are displayed in Figures 4 and 5, respectively. The characteristic form of the native starch of bitter cassava is observed in Figure 4, the granules are oval and/or round truncated with cuts in random directions, in only one of its ends. Bitter cassava starch exhibits a bimodal granule size distribution with small granules of $5.7 \mu \mathrm{m}$ and medium granules of $9.6 \mu \mathrm{m}^{[42,43]}$. The surface of the native bitter cassava starch is largely smooth with no cracks, fissures or pores; however the presence of surface erosions is evident (see Figure 4b). These erosions may be the result that the native starch was naturally oxidized and that the extraction process caused granule damage. When comparing the morphology of the modified starches with that of the native starch, it is notorious that the succinylated samples show more rough surfaces, with the presence of specific protuberances, but maintaining their granular structure. It is also clear that the materials lost the edge definition, forming agglomerates. These observations confirm that SA primarily attacked the surface of the granule during the succinylation reaction. These results are consistent with those described in the literature ${ }^{[34,42,44]}$. 
a)

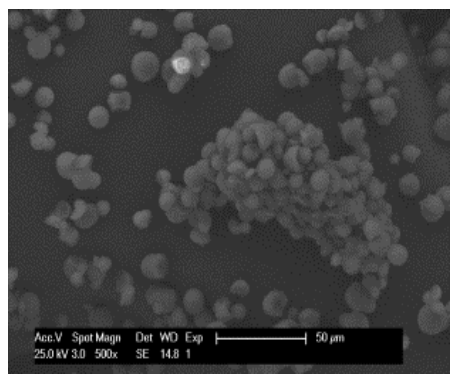

b)

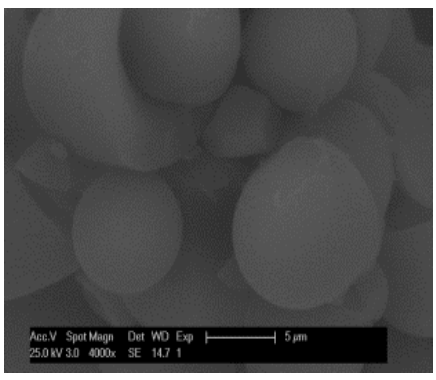

c)

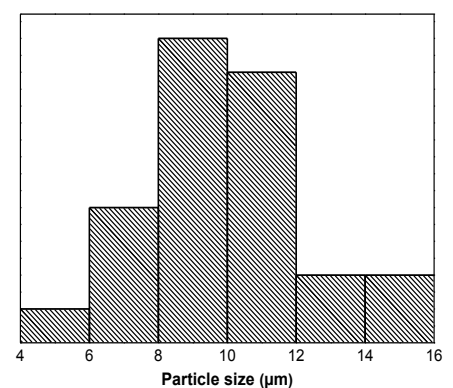

Figure 4. SEM micrographs of NS: a) 1000× and b) 4000×; c) particle size distribution.

The diameters of small granules, in general, are larger than the native bitter cassava starch, E1 $(5.9 \mu \mathrm{m})$, E2 $(5.2 \mu \mathrm{m})$, E3 $(5.3 \mu \mathrm{m})$, E4 $(6.3 \mu \mathrm{m})$, E5 $(6.0 \mu \mathrm{m})$ and E7 $(6.7 \mu \mathrm{m})$ (see Figure 5). Shogren et al. ${ }^{[15]}$ described that incorporating SA as a substituent in starch chains increases the particle size. For the medium particles it was obtained that the majority of succinylated starches decreased in size E1 $(8.4 \mu \mathrm{m})$, E2 $(9.8 \mu \mathrm{m})$, E3 $(9.0 \mu \mathrm{m})$, E4 $(8.7 \mu \mathrm{m})$, E5 $(8.7 \mu \mathrm{m})$ and E7 $(10.4 \mu \mathrm{m})$, indicating that the modification caused granule fracture. It should be noted that $\mathrm{E} 7$, presented the largest diameter distribution of both small and medium granules, in good agreement with its greater DS. 
a)

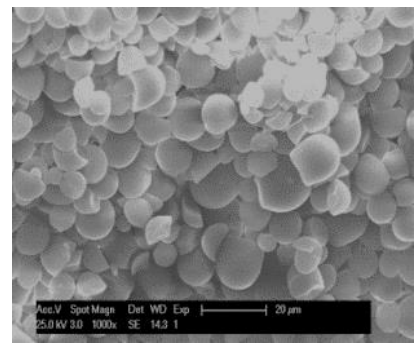

b)

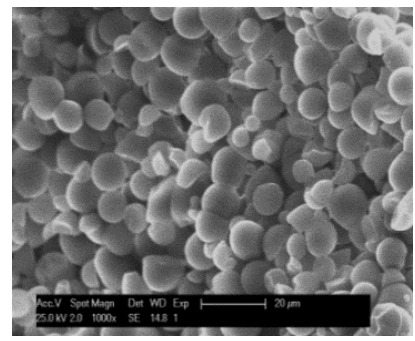

c)

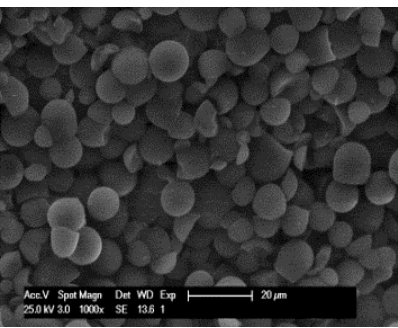

d)

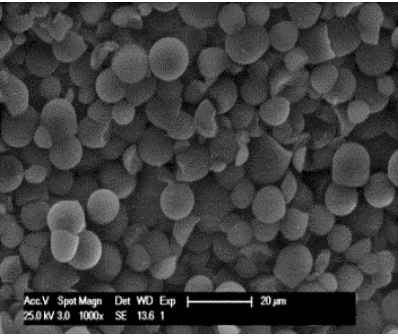

e)

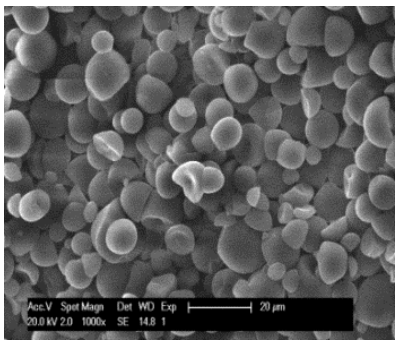

f)

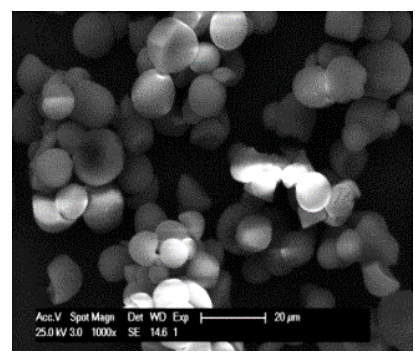

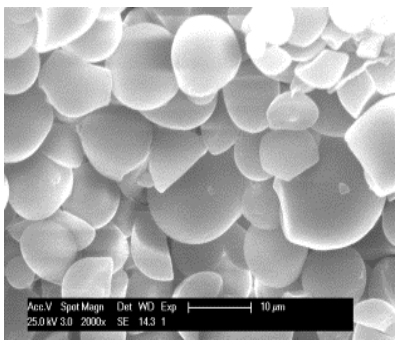
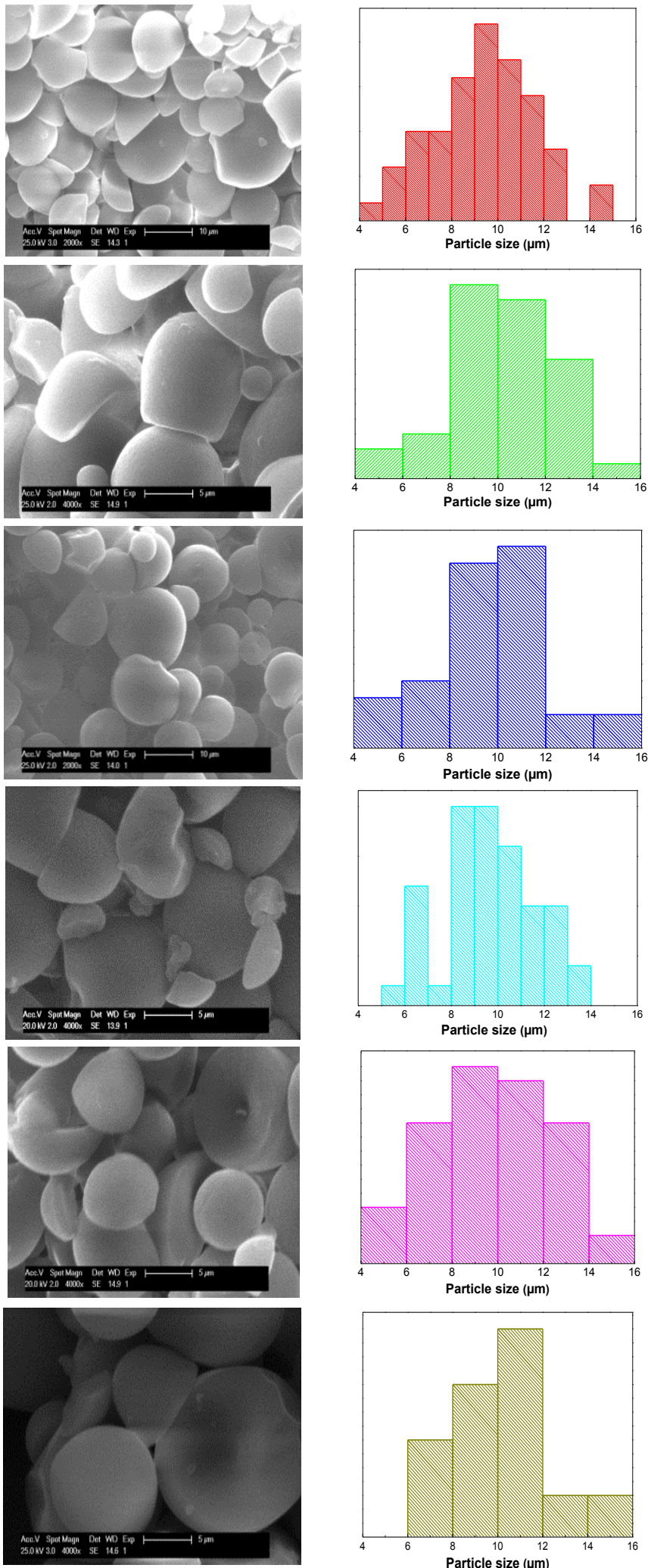

Figure 5. SEM micrographs at 1000× (left), at 4000× (center) and granule size distribution (right) of: a) E1, b) E2, c) E3, d) E4, e) E5 and f) E7. 


\subsection{Absorption capacity of succinylated starches}

The absorption capacity $\left(\mathrm{H}^{\infty}\right)$ in distilled water and at different salts $\left(\mathrm{NaCl}, \mathrm{KCl}, \mathrm{MgCl}_{2}\right.$ and $0.9 \% \mathrm{FeCl}_{3}$ ) during $24 \mathrm{~h}$ at room temperature (time that equilibrium is reached) was studied and the results are presented in Table 2.

Table 2. Absorption capacity in different media of succinylated starches

\begin{tabular}{cccccc}
\hline \multirow{2}{*}{ Sample } & \multicolumn{5}{c}{ Absorption capacity, $\mathbf{H}^{\mathbf{\infty}}$ (\%) } \\
\cline { 2 - 6 } & $\mathbf{H}_{2} \mathbf{O}$ & $\mathbf{N a C l}$ & $\mathbf{K C l}$ & $\mathbf{M g C l}_{\mathbf{2}}$ & $\mathbf{F e C l}_{\mathbf{3}}$ \\
\hline E1 & 5124 & 3474 & 3050 & 2180 & 1543 \\
E2 & 2803 & 6298 & 5867 & 3210 & 2845 \\
E3 & 2813 & 4680 & 4045 & 2345 & 1657 \\
E4 & 5397 & 6364 & 5896 & 3567 & 2145 \\
E5 & 4615 & 8053 & 7234 & 5211 & 3200 \\
E7 & 4137 & 3906 & 3299 & 2034 & 1355 \\
\hline
\end{tabular}

All succinylated starches absorbed more than 100 times their own weight in water. The products with the highest absorption capacities in water are those where $\mathrm{Na}_{2} \mathrm{SO}_{4}$ is used as catalyst (E4) and $\mathrm{NaOH}(\mathrm{E} 1)$. Ionic and hydrophilic groups (-COO- and $-\mathrm{COOH}$ ) are present in the structure of these materials; the incorporation of these groups generates an increase in water absorption capacity. Succinic acid is a diprotic acid whose $\mathrm{pK}_{\mathrm{a}}$ values are $\mathrm{pK}_{\mathrm{a} 1}=4.21$ and $\mathrm{pK}_{\mathrm{a} 2}=5.64$. At the $\mathrm{pH}$ of the distilled water, the carboxyl groups of the added succinic anhydride are ionized, which causes the matrix to expand due to the increasing electrostatic repulsions among them ${ }^{[45]}$. In contrast, the lowest absorption capacities correspond to succinylated starches catalyzed with the lowest concentrations of $\mathrm{Na}_{2} \mathrm{CO}_{3}$ (E2 and E3). This is probably due to the high degree of pseudo-crosslinking caused by the cooperative forces of the multiple hydrogen bonds between the substituent groups.

On the other hand, E1 and E7 esters have a normal polyelectrolytic behavior against all the salts studied; that is, increasing the ionic strength of the solution decreases the water absorption. The presence of counterions in the medium increases the ionic strength, the expansion of the network decreases due to the shielding effect of the charged ions bounded to the network and the reduction in the osmotic pressure difference between the gel and the external solution ${ }^{[45,46]}$. However, E2, E3, E4 and E5 esters showed antipolyelectrolytic behavior, where they swell more in saline solutions $\left(\mathrm{NaCl}, \mathrm{KCl}, \mathrm{MgCl}_{2}\right.$ and 
$\mathrm{FeCl}_{3}$ ) than in water. In these solutions, a cationic exchange could occur between the dissociated ions of the salt and the $\mathrm{H}_{3} \mathrm{O}^{+}$generated by the ionization of the functional groups of the gel, which would cause a matrix expansion [10-12]. In this case, the predominant absorption capacity factor would be the gel nature and not the medium characteristics.

The difference found in the absorption capacity of succinylated starches in the different saline solutions could be due to the effects of the ionic radius of the cation, which increases the charge of the cation ${ }^{[47]}$.

It is well known that $\mathrm{pH}$ is a critical parameter that can influence the absorption capacity of materials. Therefore, the absorption capacity in the balance of succinylated starches in different buffer solutions in a $\mathrm{pH}$ range from 4.0 until 10.1 was studied. The results are presented in Figure 6, and as can be seen, all the materials presented sensitivity to $\mathrm{pH}$. When the $\mathrm{pH}$ is 4.0 , the absorption capacity is low because the carboxyl groups are protonated, at this point the $\mathrm{pH}_{<} \mathrm{pK}_{\mathrm{a} 1}$ of $-\mathrm{COOH}$. For $\mathrm{E} 1$ and $\mathrm{E} 3$ esters, the absorption capacity was high, caused by the hydrolysis of the material, resulting in shorter chains that are able to absorb a greater percentage of water. This hydrolysis was confirmed by the loss of mass occurred during the test. At pHs between 4.0 and 6.0, the ionization of the $-\mathrm{COOH}$ occurred, increasing the absorption capacity. The apparent acid dissociation constant of the ionizable groups of $\mathrm{SA}$ is $\mathrm{pK}_{\mathrm{a}}=4.90$. The number of charges in the network increase with the ionization. The generated ionic units introduce electrostatic repulsions in the polymer chain, which lead to further expansion of the network ${ }^{[48]}$.

At $6.0<\mathrm{pH}<7.21$ the ionization of the acid groups continues until the maximum absorption capacity is achieved. For E2 and E4 the absorption capacity was almost constant, possibly due to a damping effect caused by the $-\mathrm{COOH} /-\mathrm{COO}^{-}$groups.

At $\mathrm{pH}$ between 8.0 and 10.1 the remaining $-\mathrm{COOH}$ groups in $\mathrm{E} 1$, E4 and $\mathrm{E} 5$ esters ionize, which cause a greater expansion of the network. On the contrary, in E2, E3 and E7 succinylated starches a pronounced drop in absorption capacity is produced. Bajpai et al. ${ }^{[49]}$ explained that at these $\mathrm{pH}$ values phosphate groups induce a diminution in absorption capacity. 


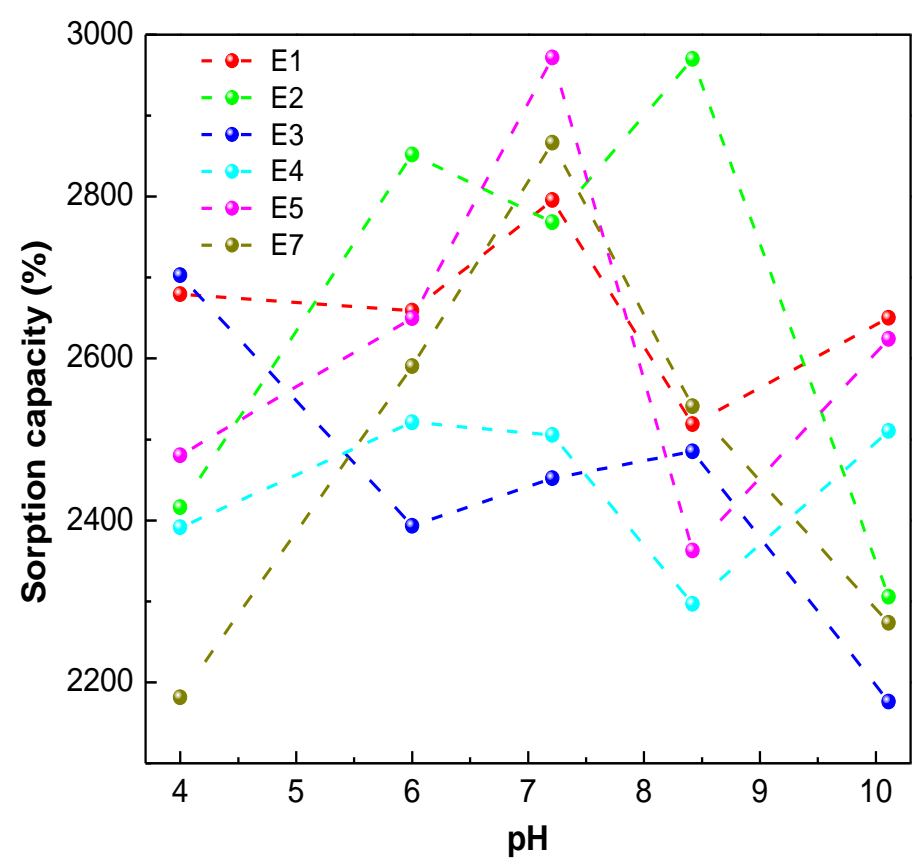

Figure 6. Absorption capacity in buffer solutions.

\subsection{Dye removal capacity}

The equilibrium adsorption, adsorption-desorption kinetics, adsorption isotherms, the effect of $\mathrm{pH}$, the effect of ionic strength and the reusability were studied to explore the effectiveness of these materials as reusable adsorbents of dyes in water of succinylated starches.

Figure 7 shows removal efficiency (RE) of the dyes $M B(50 \mathrm{mg} / \mathrm{L})$ and $\mathrm{MO}(50 \mathrm{mg} / \mathrm{L})$ for the different succinylated starches (using $6.5 \mathrm{mg}$ of starch and $25 \mathrm{~mL}$ of dye solution) after $48 \mathrm{~h}$; time in which the equilibrium is reached. In this study, the highest RE values with respect to $\mathrm{MB}$ are reached for $\mathrm{E} 5$ and $\mathrm{E} 3$, while minimum values are observed for $\mathrm{E} 2, \mathrm{E} 4$ and E7.

The MB has in its chemical structure positive charges, which can interact electrostatically with the negative charges linked to the network of succinylated starches ${ }^{[50,51]}$. On the other hand, all succinylated starches obtained low RE values for MO dye. These results are due to the chemical structure of the $\mathrm{MO}$, which contains anionic groups, which cause electrostatic repulsions, disfavoring the adsorption ${ }^{[50]}$. For this reason, the rest of the studies to evaluate the effectiveness of succinylated starches as adsorbents were performed only with MB. 


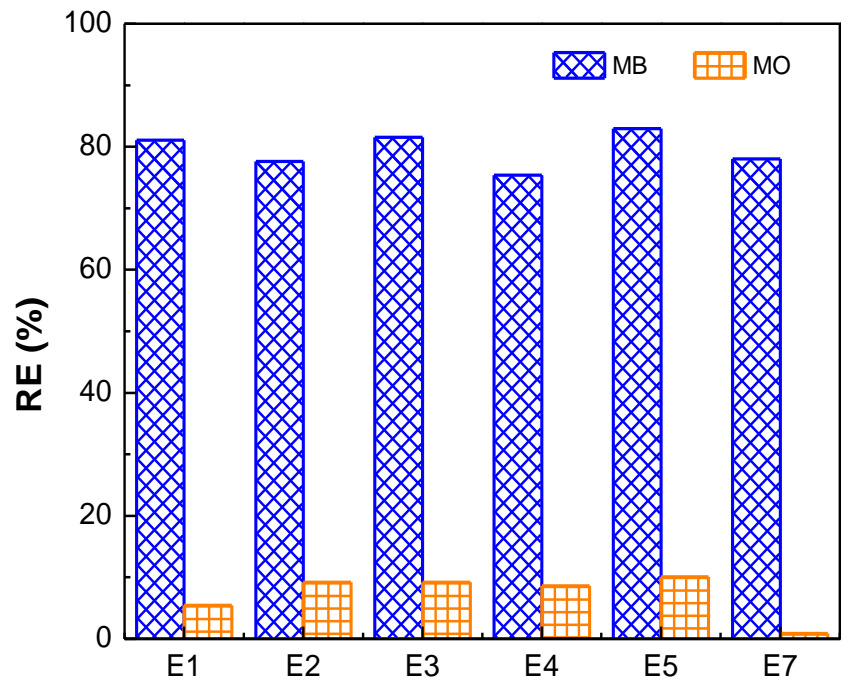

Figure 7. $\mathrm{RE}$ of $\mathrm{MB}(50 \mathrm{mg} / \mathrm{L})$ and $\mathrm{MO}(50 \mathrm{mg} / \mathrm{L})$ dyes in succinylated starches, using 6.5 $\mathrm{mg}$ of starch and $25 \mathrm{~mL}$ of dye solution.

\section{Adsorption-Desorption Kinetics}

The study of adsorption-desorption kinetics is a fundamental study in the removal of dyes in aqueous solutions. Adsorption kinetic provides important information about the adsorption mechanism and allows different adsorbents to be compared under different operating conditions for similar applications ${ }^{[9]}$. Figure 8 shows the adsorption kinetic curves of MB on succinylated starches using $6.5 \mathrm{mg}$ of starch and $25 \mathrm{~mL}$ of $\mathrm{MB}$ solution with a concentration of $50 \mathrm{mg} / \mathrm{L}$.

The adsorption capacity of MB rapidly increases in the initial stage in the first $2 \mathrm{~h}$ for all adsorbents. As time goes by, the adsorption rate decreases until the process reaches the equilibrium. At the beginning ( $\mathrm{t}=0 \mathrm{~min})$ most of the adsorption sites on the surface of the adsorbents are available to interact electrostatically with the MB molecules, as a result, high adsorption rates are obtained. As the contact time between adsorbents and MB increases, the number of sites available for adsorption decreases. Adsorption rates gradually decrease to a constant value, that is, the process reached a dynamic equilibrium ${ }^{[9,50]}$. For samples E2, E3, E5 and E7 this equilibrium is reached at ca. $24 \mathrm{~h}(\mathrm{t} \infty)$. 


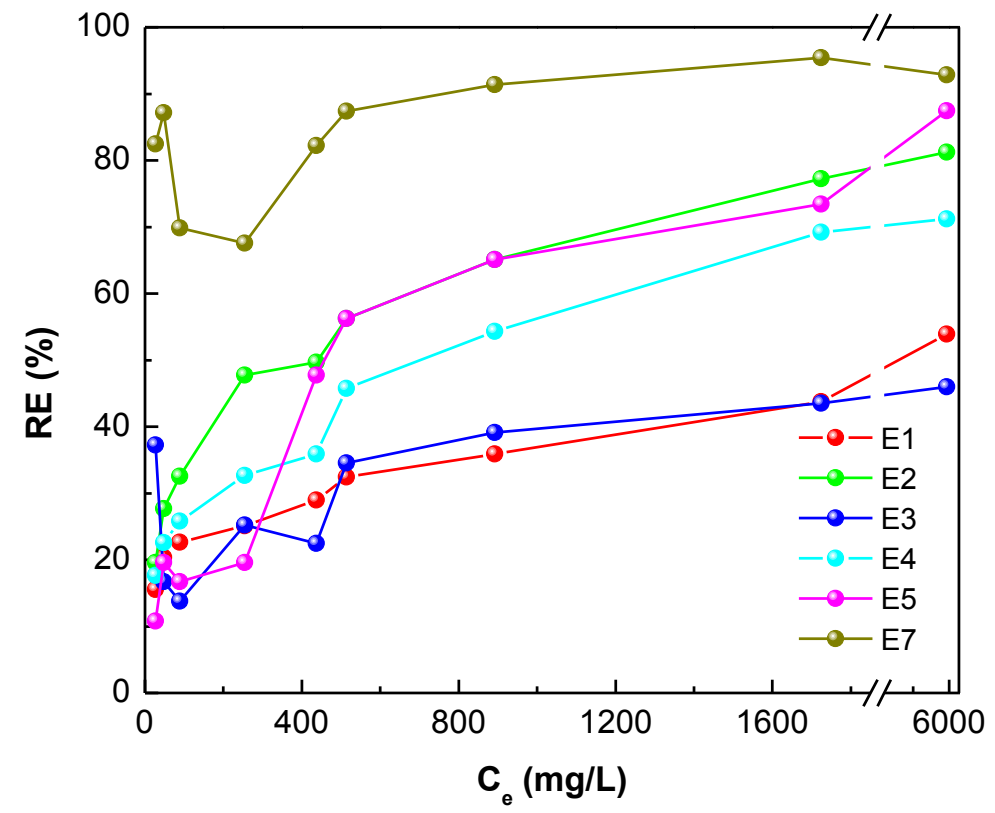

Figure 8. Adsorption kinetics of MB on succinylated starches using $6.5 \mathrm{mg}$ of starch and $25 \mathrm{~mL}$ of MB solution with a concentration of $50 \mathrm{mg} / \mathrm{L}$.

The experimental data were adjusted to the pseudo-first order model (Equation 9) and the pseudo-second order model (Equation 10).

$$
\begin{gathered}
\log \left(q_{e}-q_{t}\right)=\log \left(q_{e}\right)-\frac{k_{1}}{2.303} t \\
\frac{d q_{t}}{d_{t}}=k_{2}\left(q_{e}-q_{t}\right)^{2}
\end{gathered}
$$

Where $\mathrm{q}_{\mathrm{t}}$ is the amount of adsorbate on the absorbent $(\mathrm{mg} / \mathrm{g})$ at time $\mathrm{t}(\mathrm{min}), \mathrm{q}_{\mathrm{e}}$ is the amount of solute adsorbed per unit mass of the adsorbent in equilibrium $(\mathrm{mg} / \mathrm{g}), \mathrm{k}_{1}\left(\mathrm{~min}^{-1}\right)$ is the Lagergren adsorption rate or pseudo-first order constant, $\mathrm{k}_{2}$ is the pseudo-second order constant $(\mathrm{g} / \mathrm{mg} \times \mathrm{min})$.

The numerical values of $k_{2}$ and $q_{e}$ are obtained in the linear form of the expression of pseudo-second order (Equation 11):

$$
\frac{t}{q_{t}}=\frac{1}{k_{2} q_{e}^{2}}+\frac{1}{q_{e}} t
$$

The initial adsorption rate $\mathrm{h}(\mathrm{mg} / \mathrm{g} \times \mathrm{min})$ is obtained by linear regression of the experimental data from Equation 12.

$$
h=k_{2} q_{e}^{2}
$$

The parameters calculated from these kinetic models as well as the linear correlation coefficients $\left(R^{2}\right)$ for all succinylated starches are presented in Table S2 of SI. The 
correlations obtained for the pseudo-second order model are better than those calculated for the pseudo-first order model. This implies that the pseudo-second order model satisfactory describes the process of adsorption of MB on succinylated starches. This model indicates that the predominant MB adsorption process is chemisorption, which results from the exchange of electrons between the adsorbent and the $\mathrm{MB}{ }^{[16]}$. The succinylated starch E2 shows a markedly higher initial adsorption rate than the other modified starches, in general, a low DS of the succinylated starches positively contributes to the initial adsorption of MB.

The desorption kinetics of modified starches loaded with $M B$ are shown in Figure 9. The results show that E3 has the highest value of RE and PD. Likewise, E4, E5 and E7 are also proved to be excellent adsorbents for their ability to adsorb and desorb MB. On the contrary, E1 that has the lowest RE and one of the lowest PD is not suitable for dye removal application. E3 has smaller granule size than native starch, so it has a larger surface area, which favors the process of adsorption and desorption of MB, while E1 presents higher granule size.

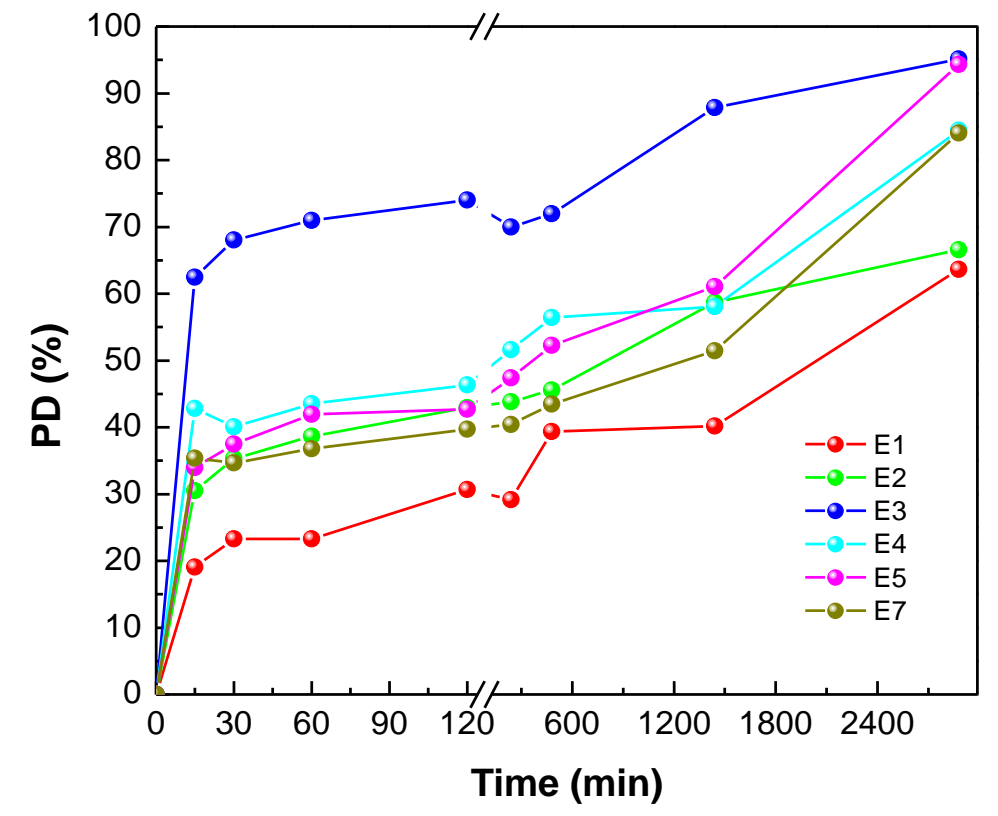

Figure 9. Desorption kinetics of MB on succinylated starches.

\section{Adsorption isotherms}

Adsorption isotherms are important to understand the mechanism of adsorption. The isotherm expresses the relationship between the amount of dye adsorbed by the 
adsorbent and the dye concentrations in the solution under equilibrium conditions. They can provide information about the adsorption mechanism, surface property and affinity of an adsorbent towards the dye ${ }^{[50]}$.

The adsorption of MB at different concentrations (2.0-50.0 mg/L) on $15 \mathrm{mg}$ of succinylated starches using $25 \mathrm{~mL}$ of dye solution was studied at room temperature under stirring. Figure 10 represents the exponential form of the adsorption isotherms of the different succinylated starches. To determine the parameters associated with the adsorption of MB, the experimental data of the adsorbents were fitted with the Langmuir (Equation 13) and Freundlich (Equation 14) models.

$$
\begin{gathered}
\frac{\mathrm{C}_{\mathrm{e}}}{\mathrm{q}_{\mathrm{e}}}=\frac{\mathrm{C}_{\mathrm{e}}}{\mathrm{q}_{\mathrm{m}}}+\frac{1}{\mathrm{k}_{\mathrm{L}} \mathrm{q}_{\mathrm{m}}} \\
\ln \left(\mathrm{q}_{\mathrm{e}}\right)=\ln \left(\mathrm{K}_{\mathrm{F}}\right)+\left(\frac{1}{n}\right) \ln \left(\mathrm{C}_{\mathrm{e}}\right)
\end{gathered}
$$

where $C_{e}$ is the equilibrium concentration of the liquid phase in $m g / L, q_{e}$ is the concentration of solute adsorbed per unit mass of adsorbent in the equilibrium in $\mathrm{mg} / \mathrm{g}, \mathrm{q}_{\mathrm{m}}$ is the maximum adsorption capacity in $\mathrm{mg} / \mathrm{g}, \mathrm{K}_{\mathrm{L}}$ is the Langmuir constant in $\mathrm{L} / \mathrm{mg}, \mathrm{K}_{\mathrm{F}}$ is the adsorption capacity in the solution phase in $\mathrm{mg} / \mathrm{g}$ and $n$ is the measurement of the cumulative magnitude and energy associated with a particular adsorption reaction in L/g.

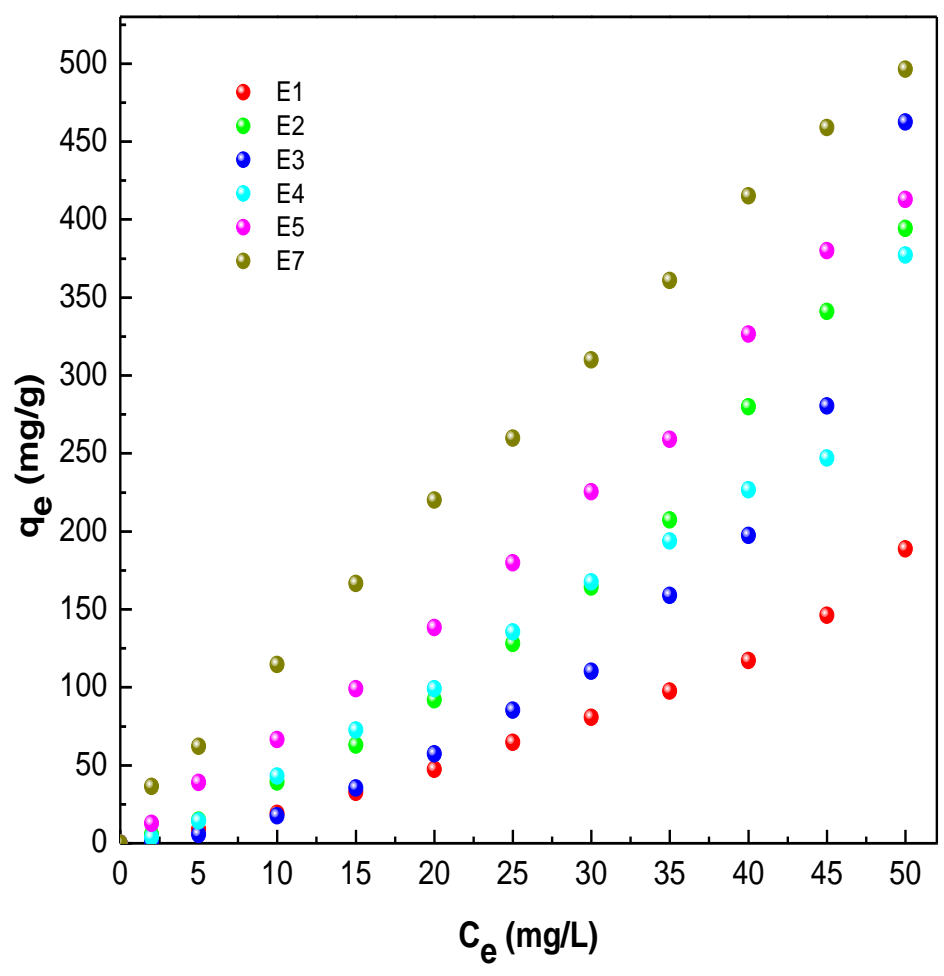

Figure 10. Adsorption isotherms of succinylated starches. 
The results showed that the experimental data are better fitted with the Freundlich model (Table S3 of Supporting Information). The Freundlich isotherm describes the adsorption process on a heterogeneous system and considers the possible formation of several layers. This model assumes that the surface of the adsorbent is heterogeneous and that the adsorption positions have different affinities, first occupying the highest affinity and then the rest ${ }^{[10-12]}$. At a higher concentration of $\mathrm{MB}$, the equilibrium adsorption capacity increases, because higher concentration gradient increases the motive diffusion force of the adsorbed dye ${ }^{[52]}$. A high DS of succinylated starches also favored the adsorption capacity of MB.

\section{Adsorption capacity of MB depending on the concentration of the adsorbent}

The removal capacity of MB (50 mg/L) was studied as a function of the concentration of the adsorbent $(0.68-15 \mathrm{mg})$ using $25 \mathrm{~mL}$ of dye solution. The results are represented in Figure 11 where is easily observed that the MB adsorption capacity of adsorbents decreases as the concentration of succinylated starches increases. This behavior can be explained as due to the all active sites are fully exposed and used at lower doses and only part of those exposed sites are occupied with $\mathrm{MB}{ }^{[52]}$. Again, the greater the DS of the succinylated starch, the greater the adsorption capacity of MB is observed.

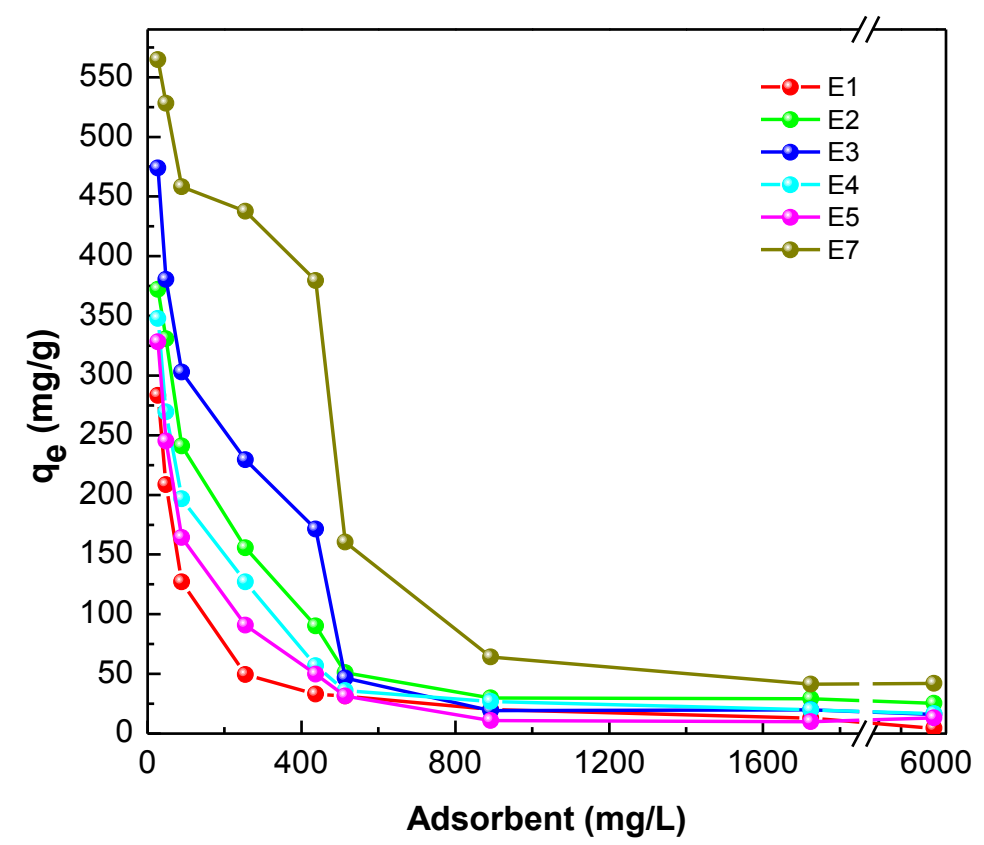

Figure 11. Removal capacity of MB (50 mg/L) as a function of the concentration of the adsorbent. 
The removal efficiency of $\mathrm{MB}$ for succinylated starches loaded with different concentrations is presented in Figure 12. It is notable that the RE of MB increases with the augment on the concentration of the adsorbent. This is due to the increase of the surface area and therefore, of the active sites in the adsorption. The succinylated starches that adsorbed more MB are those that desorbed it more, governed by chemical and physical factors. In the samples E3 and E7 different behaviors with respect to the RE of the rest are obtained. This may be due to the fact that the adsorption is not homogeneous.

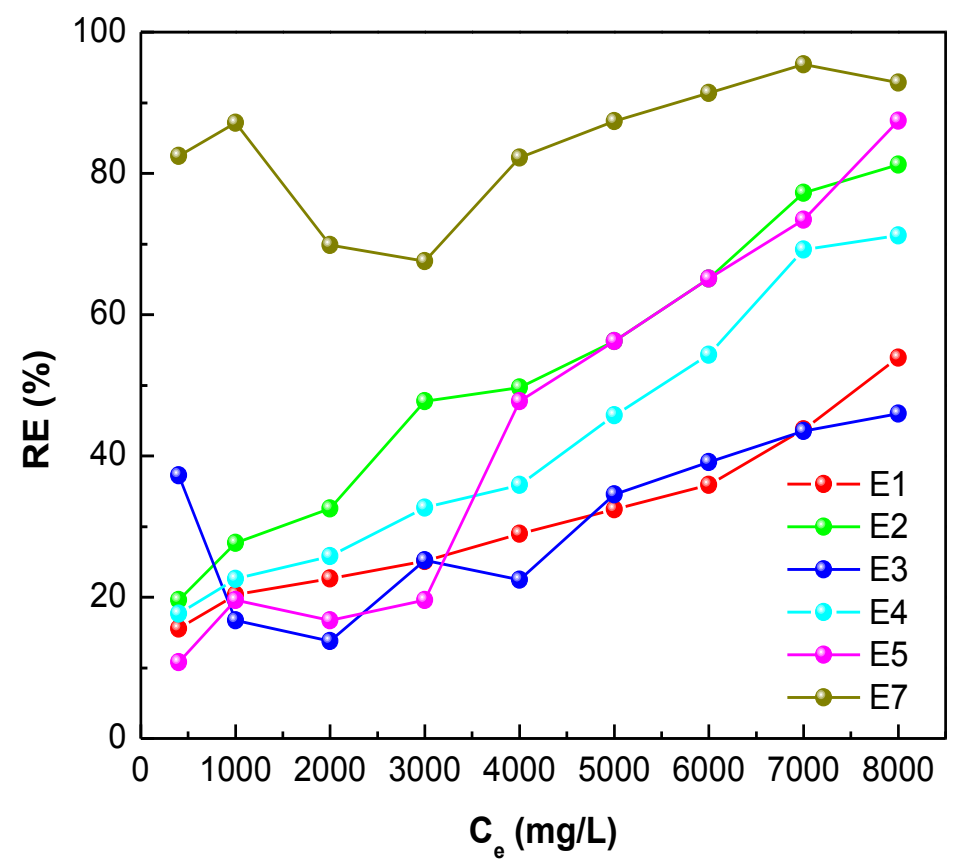

Figure 12. MB removal efficiency with succinylated starches loaded at different adsorbent concentrations.

\section{$M B$ adsorption capacity based on $\mathrm{pH}$ variation}

Generally, the adsorption capacity of the ionic adsorbents is dominated by the number of fixed charges present in their macrochain, which are strongly dependent on the medium $\mathrm{pH}$. Consequently, the influence of the $\mathrm{pH}$ is evaluated within the range of $\mathrm{pH}=4.0-9.0$, in the adsorption behavior of $\mathrm{MB}(50 \mathrm{mg} / \mathrm{L})$ on succinylated starches using $0.25 \mathrm{mg}$ and 25 $\mathrm{mL}$ of $\mathrm{MB}$ solution. Figure 13 shows the adsorption capacity of MB for succinylated starches at different $\mathrm{pH}$ values. The adsorption capacity of $\mathrm{MB}$ varies depending on the $\mathrm{pH}$ increase, as a result of changes in the electrostatic and dipole interactions between the adsorbent and the MB molecules. 


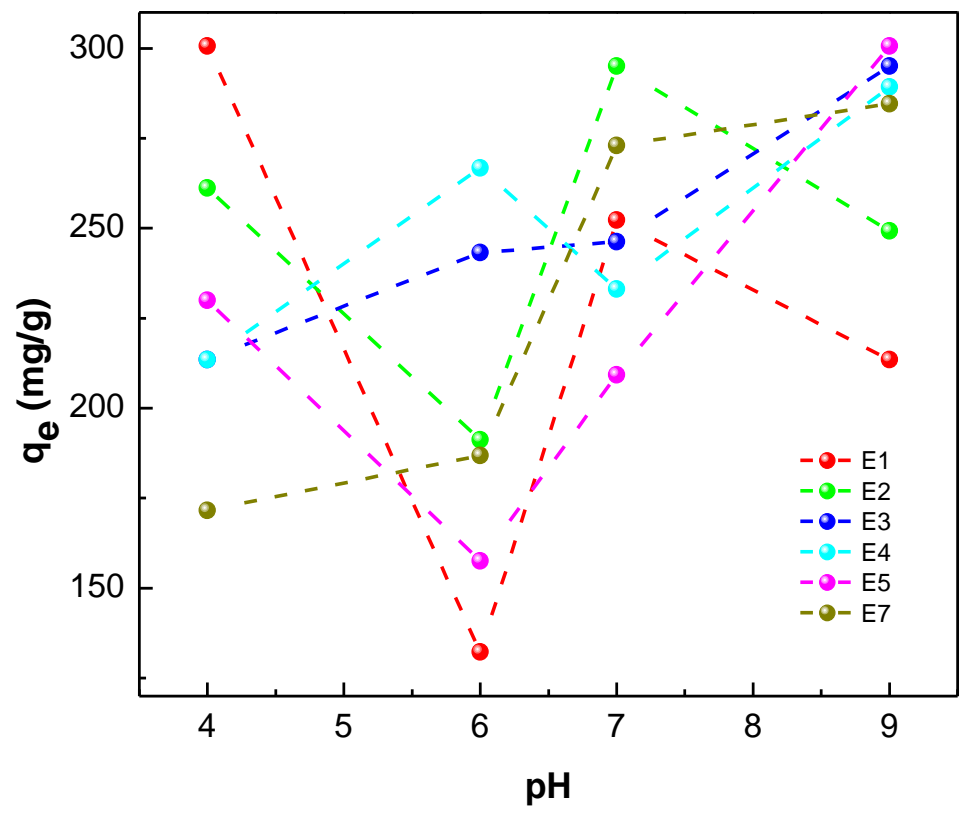

Figure 13. Adsorption capacity of $\mathrm{MB}$ on succinylated starches as a function of the $\mathrm{pH}$ of the solution.

The adsorption capacity of MB increased significantly as a result of the increase in $\mathrm{pH}$ in E7 succinylated starch. There is a sharp transition when the $\mathrm{pH}$ value increases from 6.0 to 7.0. This phenomenon can be explained considering that at $\mathrm{pH}>5.0$ (the theoretical $\mathrm{pK}_{\mathrm{a}}$ of the SA is approximately 4.9) most of the carboxylic groups are ionized and interact with the cationic molecules of MB, which lead to their adsorption and finally to stabilization. At lower $\mathrm{pH}$, the proton excess $\left(\mathrm{H}_{3} \mathrm{O}^{+}\right)$competes with the cationic groups of $\mathrm{MB}$ for adsorption sites. As a result, it is difficult for MB molecules to diffuse inside the hydrogel at lower $\mathrm{pH}$ and consequently, the adsorption capacity of the hydrogels decreases. However, at higher $\mathrm{pH}$, the $-\mathrm{COOH}$ groups along the network dissociate to form - $\mathrm{COO}^{-}$, increasing the number of ionized groups. This generates electrostatic repulsion forces between adjacent ionized groups of the polymer chains, inducing an expansion within the network. Therefore, the formation of an ionic complex between MB molecules and hydrogel networks is favored at high $\mathrm{pH}$, increasing the adsorption ${ }^{[53-55]}$.

Succinylated starches, E1 and E2, exhibit a similar behavior, except at $\mathrm{pH}=4.0$. At this point, the succinylated starch $\mathrm{E} 1$ adsorbs a greater amount of $\mathrm{MB}$, possibly due to hydrolysis. At $\mathrm{pH}>5.0$ an increase in adsorption capacity is observed due to the ionized groups. The adsorption capacity decreases at pHs from 7.0-9.0, due to the fact that at 
basic $\mathrm{pH}$ there is a blockade of the fixed adsorbent charges by the $\mathrm{Na}^{+}$ions produced by the dissociation of $\mathrm{NaOH}$ added to increase the $\mathrm{pH}$.

Succinylated starches, E3 and E4, have a low adsorption capacity at low pH. However, as the $\mathrm{pH}$ increases, the adsorption capacity of E3 does. The reason for this fact is the formation of $\mathrm{COO}^{-}$groups that interact with the $\mathrm{MB}$ molecules. In the case of succinylated starch $\mathrm{E} 4$, at a $\mathrm{pH}$ between of 6.00 and 7.00 a diminution in the adsorption capacity is observed. In the case of E5, as noted in E1 and E3, at low pH the adsorption capacity of $\mathrm{MB}$ is high because of hydrolysis. The $\mathrm{pH}$ of the dye solution is a very important factor for the removal of the dye, which can change the surface charge and the structure of adsorbent and at the same time, can promote or suppress the ionization of the adsorbent and the dye ${ }^{[34]}$.

\section{$M B$ removal capacity based on the ionic strength}

The effect of increasing the ionic strength on the MB adsorption capacity using $10 \mathrm{mg}$ of succinylated starches and $25 \mathrm{~mL}$ of the $\mathrm{MB}$ solution $(50 \mathrm{mg} / \mathrm{L})$ was investigated. The results are included in Figure 14.

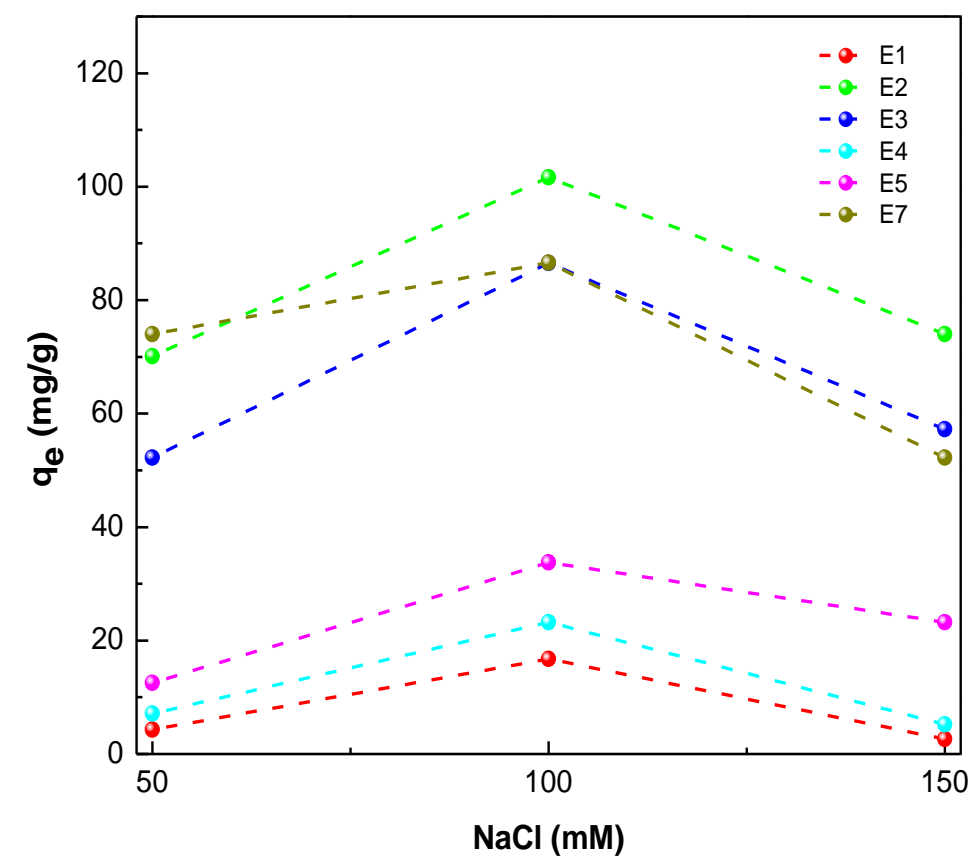

Figure 14. Adsorption capacity of $M B$ on succinylated starches as a function of onic strength using $10 \mathrm{mg}$ of adsorbent, $25 \mathrm{~mL}$ of $\mathrm{MB}$ solution with a concentration of $50 \mathrm{mg} / \mathrm{L}$. 
The adsorption capacities of succinylated starches for MB initially augments with the increase in $\mathrm{NaCl}$ concentration, due to the breakdown of the hydrogen bonds caused by $\mathrm{Na}^{+}$. As $\mathrm{NaCl}$ concentration continues to increase, adsorption capacity decreases due to excess $\mathrm{Na}^{+}$ions, which cause the suppression of electrostatic interaction by competing with MB molecules for adsorption sites on the adsorbent surface ${ }^{[56,57]}$.

Possibility of reusing adsorbents

In addition to a rapid adsorption rate and high adsorption capacity, a good adsorbent should also be regenerated and reused for other adsorption. Thus, to investigate the viability in the reuse of succinylated starches, adsorption-desorption cycles of MB using $6.5 \mathrm{mg}$ of each different adsorbent and $25 \mathrm{~mL}$ of $\mathrm{MB}$ concentration solution of $50 \mathrm{mg} / \mathrm{L}$ were performed. The results found are presented in Table S4 of SI. Five cycles are performed, finding a decrease in RE for all samples as a new cycle ends and begins, due to the reduction of available adsorption sites. With respect to the PD, the succinylated starches E2, E5 and E7 show an increase as the cycle number increases, due to the presence of a greater amount of $\mathrm{MB}$ to be desorbed, that is, the one that is not able to be desorbed from the first cycle and the adsorbed MB of the second cycle and so on. The PD of $\mathrm{E7}$ is notorious, which $\mathrm{MB}$ is completely desorbed.

\section{Conclusions}

Succinylated starches were prepared from bitter cassava starch by esterification reaction catalyzed with $\mathrm{NaOH}, \mathrm{Na}_{2} \mathrm{CO}_{3}, \mathrm{Na}_{2} \mathrm{SO}_{4}$ and $\mathrm{NaCl}$ with high GS. The native starch showed $38 \%$ crystallinity, the succinylation reaction of the starch with SA maintained the X-ray diffraction pattern and the crystallinity. In general, succinylated starches presented higher thermal stability than native starch. SEM analysis revealed that SA substitution occurred on the surface of native starch small particles. Succinylated starches were superabsorbent materials, sensitive to changes in $\mathrm{pH}$ and ionic strength of the medium. Succinylated starches were able to remove dyes in water, preferably MB. The adsorption of $M B$ depends on the conditions of the medium that affected the removal capacity of $\mathrm{MB}$ with succinylated starches, such as adsorption time, concentration of adsorbate and adsorbent, change of $\mathrm{pH}$, variation of ionic strength. Succinylated starches were able to remove MB in up to five adsorption-desorption cycles, which makes them as good candidates for dye removal.

\section{Acknowledgments}

This research was funded by MINECO, Project MAT2016-78437-R, the Agencia Estatal de 
Investigación (AEI, Spain), and Fondo Europeo de Desarrollo Regional (FEDER, EU) and the Universidad del Zulia, CONDES-LUZ.

\section{References}

[1] G. Crini, P.-M. Badot, Prog. Polym. Sci. 2008, 33, 399. https://doi.org/10.1016/i.progpolymsci.2007.11.001

[2] S. Elumalai, G. Muthuraman, M. Sathya, M. Soniya, T. T. Teng, J Ind Eng Chem 2014, 20, 1958. 10.1016/j.jiec.2013.09.017

[3] G. Mezohegyi, F. P. van der Zee, J. Font, A. Fortuny, A. Fabregat, J Environ Manage 2012, 102, 148. 10.1016/j.jenvman.2012.02.021

[4] M. T. Yagub, T. K. Sen, S. Afroze, H. M. Ang, Adv. Colloid Interface Sci. 2014, 209, 172. https://doi.org/10.1016/j.cis.2014.04.002

5] S.-T. Ong, P.-S. Keng, W.-N. Lee, S.-T. Ha, Y.-T. Hung, Water 2011, 3, 157. 10.3390/w3010157

[6] J. N. Tiwari, K. Mahesh, N. H. Le, K. C. Kemp, R. Timilsina, R. N. Tiwari, K. S. Kim, Carbon 2013, 56, 173. 10.1016/j.carbon.2013.01.001

[7] A. K. Verma, R. R. Dash, P. Bhunia, J. Environ. Manage. 2012, 93, 154. https://doi.org/10.1016/i.jenvman.2011.09.012

[8] H. L. Parker, A. J. Hunt, V. L. Budarin, P. S. Shuttleworth, K. L. Miller, J. H. Clark, RSC Advances 2012, 2, 8992. 10.1039/c2ra21367b

[9] R. F. Gomes, A. C. N. de Azevedo, A. G. B. Pereira, E. C. Muniz, A. R. Fajardo, F. H. A. Rodrigues, J. Colloid Interface Sci. 2015, 454, 200. https://doi.org/10.1016/i.jcis.2015.05.026

[10] D. Soto, J. Urdaneta, K. Pernia, O. León, A. Muñoz-Bonilla, M. Fernández-García, J. Polym. Environ. 2016, 24, 343. 10.1007/s10924-016-0780-9

[11] D. Soto, J. Urdaneta, K. Pernía, O. León, A. Muñoz-Bonilla, M. Fernandez-García, Starch-Starke 2016, 68, 37. 10.1002/star.201500155

[12] D. Soto, J. Urdaneta, K. Pernía, O. León, A. Muñoz-Bonilla, M. Fernández-García, Polym. Adv. Technol. 2015, 26, 147. 10.1002/pat.3439

[13] O. León, D. Soto, D. López, A. Muñoz-Bonilla, M. Fernández-García, Starch - Stärke 2019, 71, 1900112. 10.1002/star.201900112

[14] S. Dumitriu, Polysaccharides: Structural Diversity and Functional Versatility, Second Edition, CRC Press, Taylor \& Francis Group 2004. 
[15] R. L. Shogren, A. Viswanathan, F. Felker, R. A. Gross, Starch - Stärke 2000, 52, 196. 10.1002/1521-379x(200007)52:6/7<196::aid-star196>3.0.co;2-4

[16] S. Xu, J. Wang, R. Wu, J. Wang, H. Li, Chem. Eng. J. 2006, 117, 161. 10.1016/j.cej.2005.12.012

[17] H. Bai, Q. Zhang, T. He, G. Zheng, G. Zhang, L. Zheng, S. Ma, Appl. Clay Sci. 2016, 124-125, 157. 10.1016/j.clay.2016.02.007

[18] W. T. Tsai, C. Y. Chang, C. H. Ing, C. F. Chang, J. Colloid Interface Sci. 2004, 275, 72. 10.1016/j.jcis.2004.01.072

[19] FAO, Guía Técnica para producción y análisis de almidón de yuca, Boletín de servicios agrícolas de la FAO 163, Roma 2007.

[20] AOAC, Official Methods of Analysis. 18th Association of Official Analytical Chemists. Washington, USA 2010.

[21] D. K. Kweon, J. K. Choi, E. K. Kim, S. T. Lim, Carbohydr. Polym. 2001, 46, 171. http://dx.doi.org/10.1016/S0144-8617(00)00300-3

[22] S. Bruckner, J. Appl. Crystallogr. 2000, 33, 977. doi:10.1107/S0021889800003617

[23] A. Broido, Journal of Polymer Science Part A-2: Polymer Physics 1969, 7, 1761. 10.1002/pol.1969.160071012

[24] A. Almasian, M. Parvinzadeh Gashti, M. E. Olya, G. Chizari Fard, Desalination and Water Treatment 2016, 57, 20837. 10.1080/19443994.2015.1112841

[25] W. Xie, Y. Wang, Starch - Stärke 2011, 63, 190. 10.1002/star.201000126

[26] S. Garg, A. K. Jana, J. Appl. Polym. Sci. 2011, 119, 1383. 10.1002/app.32513

[27] R. L. Shogren, Carbohydr. Polym. 2003, 52, 319. https://doi.org/10.1016/S01448617(02)00305-3

[28] L. Ren, M. Jiang, L. Wang, J. Zhou, J. Tong, Carbohydr. Polym. 2012, 87, 1874. 10.1016/j.carbpol.2011.08.070

[29] P. N. Bhandari, R. S. Singhal, Carbohydr. Polym. 2002, 47, 277. http://dx.doi.org/10.1016/S0144-8617(01)00202-8

[30] M. Sharma, A. K. Singh, D. N. Yadav, S. Arora, R. K. Vishwakarma, Lwt 2016, 73, 52. 10.1016/j.Iwt.2016.05.034

[31] C. Mutungi, F. Rost, C. Onyango, D. Jaros, H. Rohm, Starch - StÃarke 2009, 61, 634. 10.1002/star.200900167

[32] M. G. Lomeli-Ramirez, S. G. Kestur, R. Manriquez-Gonzalez, S. Iwakiri, G. B. de Muniz, T. S. Flores-Sahagun, Carbohydr Polym 2014, 102, 576. 10.1016/j.carbpol.2013.11.020 
[33] C. Camargo, P. Colonna, A. Buleon, D. Richard-Molard, J. Sci. Food Agric. 1988, 45, 273. 10.1002/jsfa.2740450311

[34] J. Xu, C.-w. Zhou, R.-z. Wang, L. Yang, S.-s. Du, F.-p. Wang, H. Ruan, G.-q. He, Carbohydr. Polym. 2012, 87, 2137. 10.1016/j.carbpol.2011.10.035

[35] M. Chen, T. Yin, Y. Chen, S. Xiong, S. Zhao, Starch - Stärke 2014, 66, 985. 10.1002/star.201400015

[36] S. Mathew, T. Abraham, Food Chem. 2007, 105, 579. 10.1016/j.foodchem.2007.04.032

[37] O. Leon, D. Soto, A. Antunez, R. Fernandez, J. Gonzalez, C. Pina, A. Munoz-Bonilla, M. Fernandez-Garcia, Int. J.Biol. Macromol. 2019, 136, 813 10.1016/j.ijbiomac.2019.06.131

[38] P. S. Hornung, C. S. de Oliveira, M. Lazzarotto, S. R. da Silveira Lazzarotto, E. Schnitzler, J. Therm. Anal. Calorim. 2016, 123, 2129. 10.1007/s10973-015-4706-x

[39] B. Jankovic, Carbohydr Polym 2013, 95, 621. 10.1016/j.carbpol.2013.03.038

[40] P. Pineda-Gómez, N. C. Angel-Gil, C. Valencia-Muñoz, A. Rosales-Rivera, M. E. Rodríguez-García, Starch - Stärke 2014, 66, 691. 10.1002/star.201300210

[41] A. Rajan, V. S. Prasad, T. E. Abraham, Int. J.Biol. Macromol. 2006, 39, 265. 10.1016/j.ijbiomac.2006.04.006

[42] M. Ovando-Martinez, K. Whitney, B. Ozsisli, S. Simsek, J. Food Process. Preserv. 2017, 41, e12872. 10.1111/jpp. 12872

[43] J. Moraes, F. S. Alves, C. M. L. Franco, Starch - Stärke 2013, 65, 200. 10.1002/star.201200059

[44] C. M. Niu, S. Y. Li, Y. X. Gong, Advanced Materials Research 2014, 1033-1034, 346. 10.4028/www.scientific.net/AMR.1033-1034.346

[45] Esterification of Polysaccharides., Springer Laboratory. Springer, Berlin, Heidelberg 2006.

[46] Z. Mao, C. Q. Yang, J. Appl. Polym. Sci. 2001, 79, 319. 10.1002/10974628(20010110)79:2<319::aid-app140>3.0.co;2-v

[47] R. Liang, H. Yuan, G. Xi, Q. Zhou, Carbohydr. Polym. 2009, 77, 181. 10.1016/j.carbpol.2008.12.018

[48] Y. Yin, X. Ji, H. Dong, Y. Ying, H. Zheng, Carbohydr. Polym. 2008, 71, 682. http://dx.doi.org/10.1016/i.carbpol.2007.07.012

[49] J. Bajpai, S. Mishra, A. K. Bajpai, J. Appl. Polym. Sci. 2007, 106, 961. 10.1002/app.26703

[50] G. Gong, F. Zhang, Z. Cheng, L. Zhou, Int. J. Biol. Macromol. 2015, 81, 205. 
[51] E. S. Dragan, D. F. Apopei Loghin, Chem. Eng. J. 2013, 234, 211. 10.1016/j.cej.2013.08.081

[52] T. Liu, Y. Li, Q. Du, J. Sun, Y. Jiao, G. Yang, Z. Wang, Y. Xia, W. Zhang, K. Wang, H. Zhu, D. Wu, Colloids Surf B Biointerfaces 2012, 90, 197. 10.1016/j.colsurfb.2011.10.019

[53] R. Coşkun, A. Delibaş, Polym. Bull. 2011, 68, 1889. 10.1007/s00289-011-0664-z

[54] S. Li, Bioresour Technol 2010, 101, 2197. 10.1016/j.biortech.2009.11.044

[55] Y. Zhou, S. Fu, H. Liu, S. Yang, H. Zhan, Polymer Engineering \& Science 2011, 51, 2417. 10.1002/pen.22020

[56] J. Sokolowska-Gajda, H. S. Freeman, A. Reife, Dyes Pigm. 1996, 30, 1. https://doi.org/10.1016/0143-7208(95)00048-8

[57] N. Bensalah, M. A. Q. Alfaro, C. A. Martínez-Huitle, Chem. Eng. J. 2009, 149, 348. 10.1016/j.cej.2008.11.031

\section{LEGEND OF FIGURES}

Scheme 1. (a) Ring opening of succinic anhydride, (b) Mono-substitution of succinic anhydride on starch and (c) Di-substitution of succinic anhydride on starch.

Figure 1. Apparent viscosity as a function of shear rate for the different samples Figure 2. X-ray diffractograms of starch and its derivatives.

Figure 3. Thermograms (left) and derivative of thermograms curves (right) of native and succinylates starches.

Figure 4. SEM micrographs of NS: a) 1000× and b) 4000x; c) particle size distribution.

Figure 5. SEM micrographs at $1000 \square$ (left), at $4000 \square$ (center) and granule size distribution (right) of: a) E1, b) E2, c) E3, d) E4, e) E5 and f) E7.

Figure 6. Absorption capacity in buffer solutions.

Figure 7. RE of $M B(50 \mathrm{mg} / \mathrm{L})$ and $M O(50 \mathrm{mg} / \mathrm{L})$ dyes in succinylated starches, using 50 $\mathrm{mg}$ of starch and $25 \mathrm{~mL}$ of dye solution.

Figure 8. Adsorption kinetics of MB on succinylated starches using $50 \mathrm{mg}$ of starch and 25 $\mathrm{mL}$ of $\mathrm{MB}$ solution with a concentration of $50 \mathrm{mg} / \mathrm{L}$.

Figure 9. Desorption kinetics of MB on succinylated starches.

Figure 10. Adsorption isotherms of succinylated starches.

Figure 11. Removal capacity of MB (50 mg/L) as a function of the concentration of the adsorbent. 
Figure 12. MB removal efficiency with succinylated starches loaded at different adsorbent concentrations.

Figure 13. Adsorption capacity of $\mathrm{MB}$ on succinylated starches as a function of the $\mathrm{pH}$ of the solution.

Figure 14. Adsorption capacity of $M B$ on succinylated starches as a function of onic strength using $150 \mathrm{mg}$ of adsorbent, $25 \mathrm{~mL}$ of MB solution with a concentration of $50 \mathrm{mg} / \mathrm{L}$. 